\title{
Nonlinear Flutter Analysis for a Long-Span Suspension Bridge
}

\author{
Jieshan Liu $\mathbb{D}^{1,2}$ Fan Wang $\mathbb{D}^{1,2}$ Yang Yang $\mathbb{D}^{1,2}$ and Renhuai Liu ${ }^{1,2}$ \\ ${ }^{1}$ School of Mechanics and Construction Engineering, Jinan University, Guangzhou 510632, China \\ ${ }^{2}$ MOE Key Laboratory of Disaster Forecast and Control in Engineering, Jinan University, Guangzhou 510632, China
}

Correspondence should be addressed to Fan Wang; twfan@jnu.edu.cn

Received 18 February 2021; Revised 17 June 2021; Accepted 23 June 2021; Published 20 July 2021

Academic Editor: Letícia Fleck Fadel Miguel

Copyright (c) 2021 Jieshan Liu et al. This is an open access article distributed under the Creative Commons Attribution License, which permits unrestricted use, distribution, and reproduction in any medium, provided the original work is properly cited.

\begin{abstract}
The wind-induced flutter of the long-span suspension bridge structure is extremely harmful to the bridge. Therefore, it is necessary to study the nonlinear problem of wind-induced flutter. Here, the nonlinear flutter problem of a long-span suspension bridge with cubic torsional stiffness is analyzed by the equivalent linearization method. The system has Hopf bifurcation and limit cycle oscillations (LCOs) under critical wind speed. Replacing the nonlinear stiffness term of the original nonlinear equation with the equivalent linear stiffness, we can obtain the equivalent linearized equation of the nonlinear flutter system and the solution, critical wind speed, and flutter frequency of the suspension bridge flutter system. At the same time, the system has a limit cycle vibration, and the Hopf bifurcation point is obtained. Compared with the numerical method, the calculation results are consistent. The influence of the damping ratio on the flutter system is analyzed. Increasing the system damping ratio can increase the flutter critical wind speed and reduce the amplitude of LCOs. The influence of cubic torsional stiffness on the flutter system is analyzed. The increase of the cubic stiffness coefficient does not change the critical state of flutter, but reduces the amplitude of LCOs.
\end{abstract}

\section{Introduction}

With the increase of the bridge span, especially the longspan suspension bridge, the structure tends to soften. Its damping and natural vibration frequency of the structure will decrease. The influence of wind on the bridge can easily cause wind vibration. Among them, flutter is the most serious wind-induced vibration phenomenon because the vibration will radiate when flutter occurs, and the amplitude of vibration will gradually increase with the increase of time and wind speed, which will seriously damage the bridge. Therefore, flutter cannot occur throughout the life cycle of the bridge. The flutter problem can be regarded as a vibration produced by the self-excited forces caused by airflow acting on the bridge deck center, according to Scanlan's self-excited flutter model; the model assumes that the two-degree bridge deck model is excited by self-excited force when it vibrates [1]. The self-excited force is expressed as a linear function of vibration displacement and velocity in the form of flutter derivative; then, the flutter derivatives are the function of reduced wind speed, and they can be obtained through wind tunnel tests or numerical simulations. The flutter analysis based on linear elasticity and self-excited force theory can accurately calculate the critical state of the bridge, and when the wind speed exceeds the critical flutter wind speed, the bridge vibration will increase rapidly and becomes unstable. This is a structural instability where the equilibrium state of the structure begins to lose its stability under the action of external forces, and a slight disturbance, which is practically unavoidable, gradually increases the deformation and finally causes the structure to break down. The instability of the bridge system at the critical state of flutter is Hopf bifurcation; when wind speed exceeds it, there will be a phenomenon such as the Tacoma Narrows Bridge and the finiteamplitude periodic vibration that occurrs in the wind tunnel test, that is, the limit cycle oscillations (LCOs). LCO is a steady-state motion such as a stable limit cycle that diverges from the static instability point in Hopf bifurcation; in the phase diagram, it is a closed isolated trajectory. Only the critical flutter state and Hopf bifurcation can be calculated if based on a linear flutter system. However, the LCO is the solution of a nonlinear system. Therefore, a nonlinear system 
based on the nonlinear characteristics of large-span suspension bridges is needed to analyze the Hopf bifurcation type and LCO after the bifurcation.

On the one hand, for many long-span suspension bridges, the effects of geometric and structural nonlinearities are prominent due to the reduced structural stiffness, making the bridge section vibrations negligible. On the other hand, structurally, the steel box girder in the bridge system is similar to the aircraft wing as in Figure 1, in which Figure 1(a) is a construction of the steel box girder and Figure 1(b) is a construction of the aircraft wing. The nonlinear flutter problem of long-span suspension bridges is analogous to the flutter problems of large aspect ratio flexible wings, which should be studied theoretically using the nonlinear dynamics analysis method for the Hopf bifurcation problem, in which the limit cycle oscillations (LCOs) occur after the bridge system enters into a flutter.

At present, the nonlinear factors of nonlinear flutter can be divided into three categories: aerodynamic self-excited force nonlinearity, geometric nonlinearity, and structural nonlinearity. Flutter was initially studied in the field of aircraft. After the Tacoma Narrow Bridge broke in the wind in 1940, experts used aircraft theory to study the flutter of the bridge and then developed it into a bridge aerodynamic theory.

In the study of nonlinear aerodynamic self-excited forces, Scanlan introduced the self-excited forces, which can be expressed as a function of the vertical and torsion velocity and displacement of the bridge deck, and the coefficients are expressed as the flutter derivatives which associated with reduced wind speed [1-5]. Scanlan pointed out that the aerodynamic self-excited forces of the bridge deck are not only a function of reduced wind speed but also related to the wind attack angle and turbulence of the bridge deck [6]. The results of the wind tunnel test and numerical simulation show that aerodynamic self-excited force has a great relationship with wind attack angle and turbulence [7-12]. Also, the nonlinearity of self-excited aero force can be analyzed by the numerical finite element method $[13,14]$.

In the study of nonlinear problems caused by the geometric factor of suspension bridges, it is a system composed of two-degree bridge deck and spring constant hangers. Mckenna established this geometrically nonlinear system [15]. When the bridge deck is subjected to torsional displacement, the change in the magnitude and direction of the elastic force of the hanger leads to geometric nonlinearity of torsion. Based on this system, the authors studied the bifurcation and LCOs of this kind of two-degree bridge deck model [15-21].

When analyzing the nonlinear problems caused by the nonlinear stiffness of the structure, the first step is to study the aircraft. Woolston once said that when the wing twists, its stiffness coefficient is a nonlinear function of the torsional angle, which is called cubic, flat spot, or hysteresis nonlinear stiffness springs [22]. In addition, Woolston also made a spring mechanism for the wings, which can be adjusted to show three types of nonlinear stiffness characteristics in order to measure its free vibration performance in a wind tunnel, and then discussed the relationship between wind speed and amplitude [23]. The cubic nonlinear stiffness coefficient is written as a cubic function of the torsion angle and has been widely used in the flutter equations of aircraft [24-29].

Dowell concluded that the nonlinear stiffness wing will exhibit LCOs when wind speed exceeds the critical wind speed in many wind tunnel tests and numerical simulations [30]. Wright recapitulated that structural nonlinearities will occur when the aircraft's components undergo large deformations, and they will exhibit cubic nonlinear stiffness when the wings undergo large deformations [31]. Chen discussed the problem of flutter LCOs of a wing with cubic nonlinear stiffness by ELM [27]. Chen established a torsional stiffness term with cubic nonlinear stiffness by determining the characteristic value of the linear system to obtain the critical flutter wind speed, and the LCO of a wind speed value was solved by the iteration method [32].

The bridge deck system of the long-span suspension bridge mostly adopts the steel box girder structure. To some extent, the steel box girder structure is similar to the large aspect ratio wing structure of aircraft. Both of them have longitudinal beams with web plate and diaphragms as in Figure 1. The webs contribute greatly to the structural rigidity. According to Younger's web shear force distribution theory, the shear stress of the web presents a nonlinear distribution when $\mathrm{H}$-shaped and I-shaped cross-section beams deform in bending and torsion $[33,34]$. On this basis, Kuhn Paul studied the longitudinal rod-web combined model. The longitudinal force acts on the longitudinal rod, so the longitudinal rod transmits force to the web, and the reaction force of the web affected it. Therefore, the relationship between force and displacement is obtained in line with Younger's theory. The longitudinal force and torsion force will show nonlinear changes with the increase of displacement [35]. Ma conducted a stiffness test on the deck system of the suspension bridge, and its torsional stiffness increased with the torsion angle during the small displacement stage, showing a strong nonlinear growth trend [36]. Therefore, this article holds that the webs in the steel box girder have a nonlinear stiffness enhancement effect on the overall structure so that the steel box girder exhibits nonlinear torsional stiffness.

In this paper, the flutter and LCOs beyond critical flutter speed of a long-span suspension bridge deck with cubic nonlinear torsional stiffness will be studied. First, based on Scanlan's flutter self-excited forces theory, the discrete test flutter derivatives were fitted to the quadratic function of the reduced wind speed. Second, considering the cubic torsional stiffness and the vibration frequency of a long-span suspension bridge, nonlinear flutter equations of Nizhou Waterway Bridge were established by referring the plane wings flutter model. Third, by replacing the nonlinear stiffness term with the equivalent linear coefficient through ELM, the critical flutter wind speed and critical flutter frequency are obtained, and at the same time, at the point of critical flutter wind speed, Hopf bifurcation and LCOs occur. 


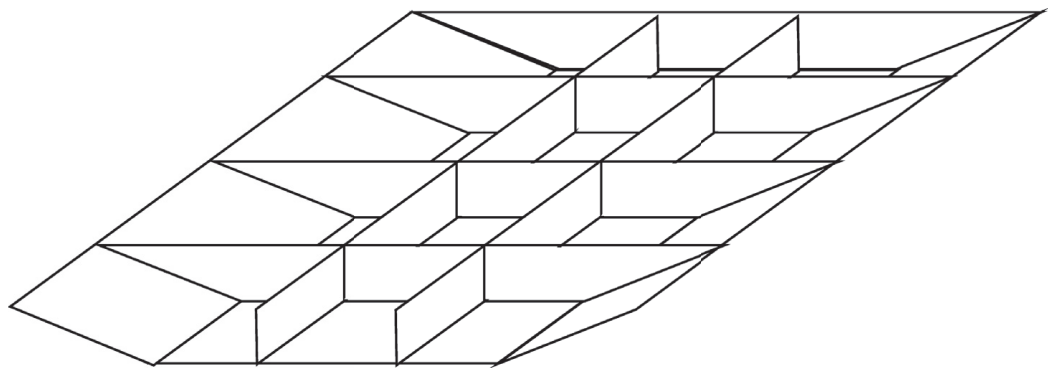

(a)

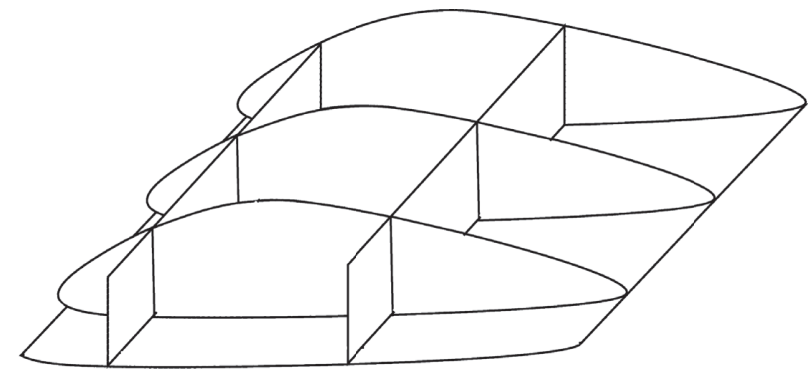

(b)

Figure 1: (a) Structure of the steel box girder of the bridge system. (b) Structure of the aircraft wing.

\section{Nonlinear Flutter Model of Bridge Deck}

The bridge flutter model is assumed as a two-dimensional rigid bridge deck suspended by two springs and oscillated in vertical (denoted by $h$ ) and torsional (denoted by $\alpha$ ) displacements, as shown in Figure 2. Two springs have vertical stiffness $k_{h}$ and torsional stiffness $k_{\alpha}$, respectively; thus, the vertical bending stiffness and torsional stiffness of a largespan suspension bridge are expressed by each springs' stiffness. The stiffness coefficients of the springs have a relationship with the first-order frequency $\omega_{h}$ or $\omega_{\alpha}$ and mass $m_{h}$ or $I$ of the actual bridge in vertical bending and torsion, that is, $k_{h}=m_{h} \omega_{h}^{2}$ or $k_{\alpha}=I \omega_{\alpha}^{2}$. Each bridge has different vibration frequencies, especially for a large-span suspension bridge, where the first-order frequencies in vertical and torsional are smaller than for other bridge types. Therefore, in this paper, the span of $1688 \mathrm{~m}$, named Nizhou Waterway Bridge, was selected as the object of study; the stiffness coefficients in the flutter model are related to the first-order self-oscillation frequency of the whole bridge. According to Scanlan's flutter theory [1] and research in aircraft [37, 38], the self-excited forces of two-degree (vertical excited force denoted by $F(L)$, torsional excited force denoted by $F(M)$ ) are acting on bridge deck center.

This bridge flutter model is widely used in many bridge flutter studies [4, 5, 9, 39-41]; it was altered from the aircraft wing flutter model by many scholars in the past.
2.1. The Cubic Nonlinear Stiffness. The bridge deck will show structural nonlinearity when taking large torsional amplitude, which can be divided into centralized and distributed nonlinearity. In this paper, the centralized nonlinearity in the structural nonlinearity of the long-span suspension bridge has been studied.

When analyzing the concentrated nonlinear stiffness of the structure, Ko Jeonghwan and Strganac Thomas expressed the nonlinear force as the force-deformation curve fitting and took the appropriate term. This article uses a concentrated nonlinear form for calculation and research $[42,43]$.

When the bridge deck has a torsional deformation, the torsional stiffness term will be related to the cubic of torsional displacement, which can also describe that it is the cubic nonlinearity stiffness $k_{\alpha}=I \omega_{\alpha}^{2}+e_{\alpha} \alpha^{3}$. It was represented as the torsional spring having cubic stiffness acting on the flutter model in Figure 2.

The flutter motion system of the bridge deck with cubic nonlinear stiffness is written as equations (1) and (2). On the left side of the equations are two-dimensional effect. On the right side of the equations are the flutter self-excited forces which are put forward by Scanlan [1]. The torsional stiffness term on the left side of the equations is written as a cubic function of torsional displacement, which means that the nonlinear cubic stiffness is related to torsional displacement: 


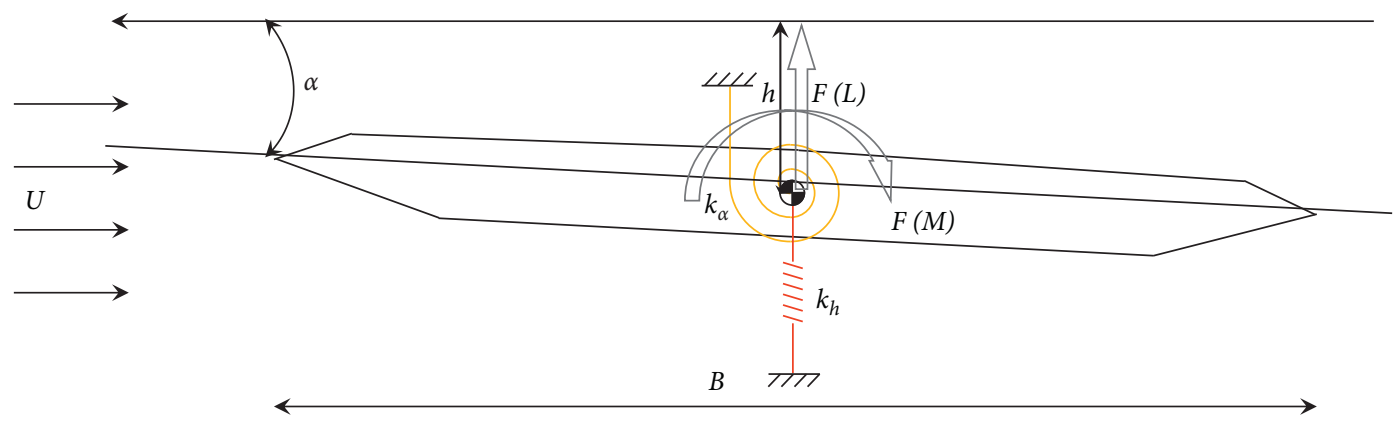

Figure 2: Two-degree bridge deck model.

$$
\begin{aligned}
& m_{h} \ddot{h}+2 \xi_{h} m_{h} \omega_{h} \dot{h}+m_{h} \omega_{h}^{2} h=\rho U^{2} B\left[K H_{1}^{*} \frac{\dot{h}}{U}+K H_{2}^{*} \frac{B \dot{\alpha}}{U}+K^{2} H_{3}^{*} \alpha+K^{2} H_{4}^{*} \frac{h}{B}\right], \\
& I \ddot{\alpha}+2 \xi_{\alpha} I \omega_{\alpha} \dot{\alpha}+I \omega_{\alpha}^{2} \alpha+e_{\alpha} \alpha^{3}=\rho U^{2} B^{2}\left[K A_{1}^{*} \frac{\dot{h}}{U}+K A_{2}^{*} \frac{B \dot{\alpha}}{U}+K^{2} A_{3}^{*} \alpha+K^{2} A_{4}^{*} \frac{h}{B}\right],
\end{aligned}
$$

$$
\begin{aligned}
C_{L} & =\pi\left(L_{\alpha} \alpha+\left(\frac{L_{h} h}{b}\right)\right), \\
C_{M} & =\pi\left(M_{\alpha} \alpha+\left(\frac{M_{h} h}{b}\right)\right) .
\end{aligned}
$$
the displacement, velocity, and acceleration of the torsional direction, $\xi_{h}$ and $\xi_{\alpha}$ are integral damping ratios, $\omega_{h}$ and $\omega_{\alpha}$ are the corresponding natural mechanical frequencies of vertical and torsional, $H_{i}^{*}$ and $A_{i}^{*}$ ( $i=1,2,3$, and 4 ) are coefficients that provided for the selfexcited aerodynamic force in a linear manner, $K$ is the reduced frequency, and $K=B \omega / U$; in addition, the reduced wind speed is $V_{r}=2 \pi / K=U / B f, f$ is vibration frequency, $\rho, U$, and $B$ stand for air density, wind speed, and width of the bridge deck, and $e_{\alpha}$ is the coefficient of cubic stiffness.

In this paper, Nizhou Waterway Bridge of Second Humen Bridge, a long-span suspension bridge with 1688 meters main span, has been taken as the research object. The correlation parameters $[32,44]$ are shown in Table 1.

2.2. Fitting Flutter Derivatives. When a suspension bridge is suffered from wind flow, the section of the main girder is subjected to aerodynamic forces in the flow field, which are aerodynamic lift $L$ and aerodynamic torque $M$, and they are expressed in the plural form of aerodynamic forces:

$$
\begin{aligned}
L & =\rho \omega^{2} b^{3} R I\left[C_{L} e^{i \omega t}\right], \\
M & =\rho \omega^{2} b^{4} R I\left[C_{M} e^{i \omega t}\right] .
\end{aligned}
$$

In equation (3), $R I$ denotes taking the real part in square brackets, where $C_{L}$ and $C_{M}$ are the peak values of aerodynamic force, which are a function of the reduced frequency or reduced wind speed for nonconstant flows, and they can be expressed by the harmonic aerodynamic coefficients $L_{\alpha}, L_{h}, M_{\alpha}$, and $M_{h}$ :
In the Scanlan aerodynamic model of self-excited force, flutter derivatives are used to represent the harmonic aerodynamic coefficients, so the flutter derivative should also be a function of the reduced wind speed (denoted by $V_{r}$ ) or reduced frequency (denoted by $K$ ); they are only associated to the shape of the cross section of the bridge girder. The values of flutter derivatives for reduced wind speed are identified by the wind tunnel or numerical simulation, and they are discrete points; thus, to solve the flutter system in this paper, these discrete points are fitted to the flutter derivative as a function of reduced wind speed by the least squares method:

$$
A_{i}^{*}, H_{i}^{*}=f\left(V_{r}\right)=f(K),
$$

where $A_{i}^{*}$ and $H_{i}^{*}(i=1,2,3$, and 4$)$ represent eight flutter derivatives. In this paper, the discrete flutter derivatives, from Hong's numerical test with the force vibration method [44], were fitted for polynomial functions of reduced wind speed:

$$
\begin{aligned}
H_{i}^{*} & =f\left(V_{r}\right)=H_{i 1}^{*} \times V_{r}+H_{i 2}^{*} \times V_{r}^{2}, \\
A_{i}^{*} & =f\left(V_{r}\right)=A_{i 1}^{*} \times V_{r}+A_{i 2}^{*} \times V_{r}^{2},
\end{aligned}
$$

where $H_{i 1}^{*}, H_{i 2}^{*}, A_{i 1}^{*}$, and $A_{i 2}^{*}$ are coefficients of functions (6) and (7), as shown in Table 2.

The fitting curves of eight flutter derivatives are shown in Figure 3, in which the dots are discrete values via the test and solid lines are fitting curves. 
TABLE 1: Parameters of the bridge flutter system.

\begin{tabular}{lcc}
\hline Name & Unit & Value \\
\hline$m$ & $\mathrm{~kg} / \mathrm{m}$ & 65649 \\
$I$ & $\mathrm{~kg} \times \mathrm{m}$ & 7808150 \\
$B$ & $\mathrm{~m}$ & 41.7 \\
$\xi_{h}$ & $(\mathrm{None})$ & 0.005 \\
$\xi_{\alpha}$ & $(\mathrm{None})$ & 0.005 \\
$\omega_{h}$ & $\mathrm{~Hz}$ & 0.07241 \\
$\omega_{\alpha}$ & $\mathrm{Hz}$ & 0.21213 \\
$e_{\alpha}$ & $(\mathrm{None})$ & $1000 m_{h} \omega_{\alpha}^{2}$ \\
\hline
\end{tabular}

TABle 2: Coefficients of flutter derivatives' function.

\begin{tabular}{lcc}
\hline Flutter derivatives & $H_{i 1}^{*}$ or $A_{i 1}^{*}$ & $H_{i 2}^{*}$ or $A_{i 2}^{*}$ \\
\hline$H_{1}^{*}$ & -0.2583 & -0.005808 \\
$H_{2}^{*}$ & -0.2032 & 0.01521 \\
$H_{3}^{*}$ & 0.07225 & -0.06389 \\
$H_{4}^{*}$ & 0.2041 & -0.02397 \\
$A_{1}^{*}$ & 0.05653 & 0.00007511 \\
$A_{2}^{*}$ & -0.01323 & 0.0002376 \\
$A_{3}^{*}$ & 0.02369 & 0.006157 \\
$A_{4}^{*}$ & -0.01045 & 0.002351 \\
\hline
\end{tabular}

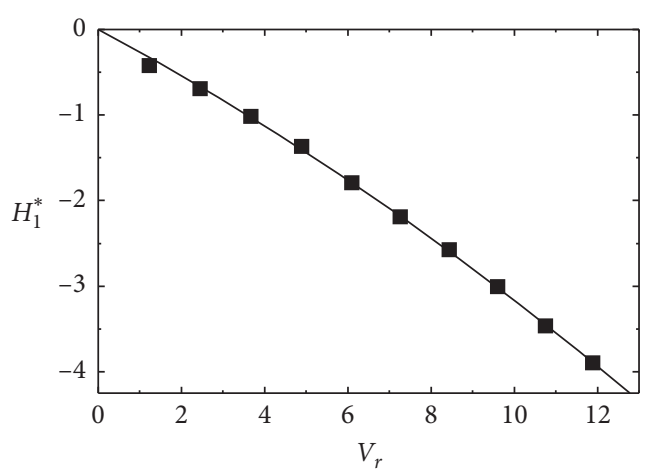

(a)

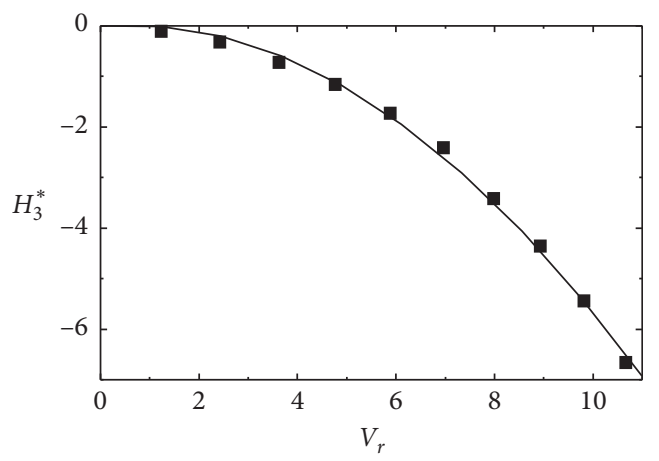

(c)

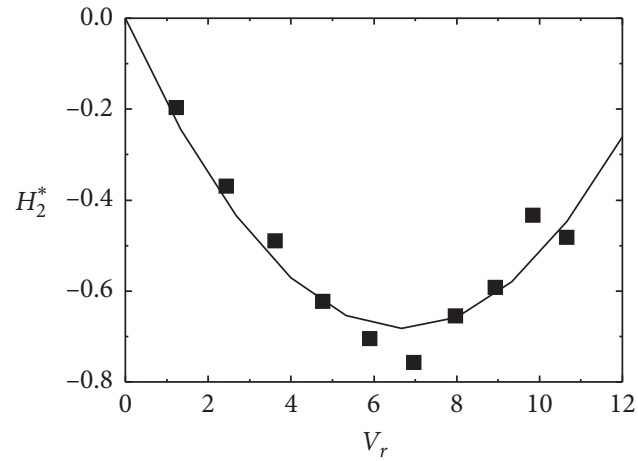

(b)

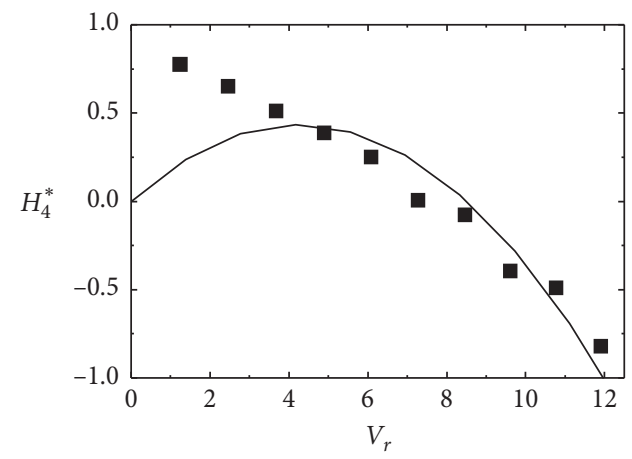

(d)

FIgURE 3: Continued. 


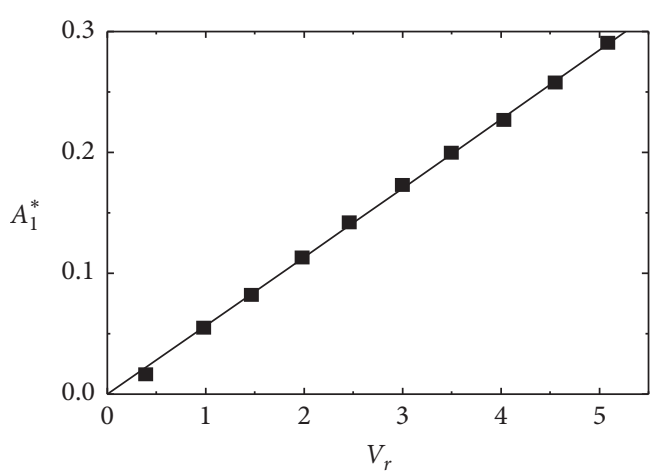

(e)

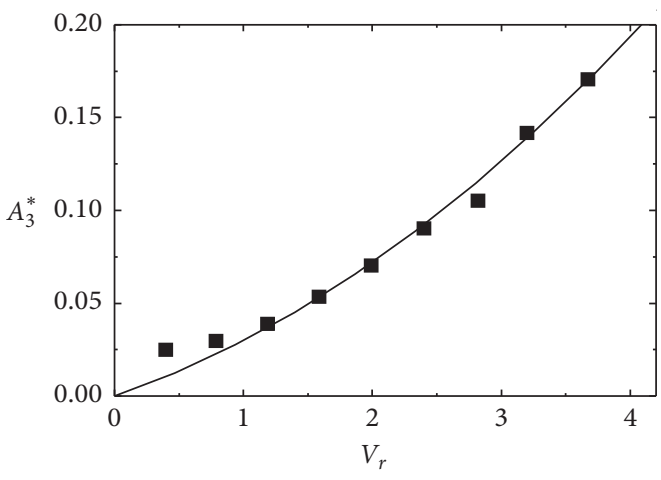

(g)

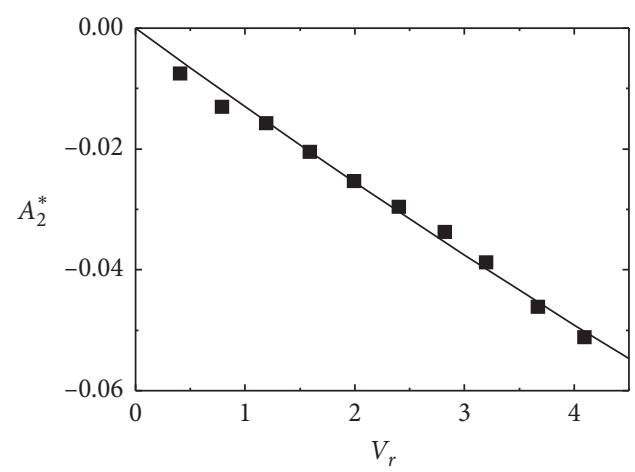

(f)

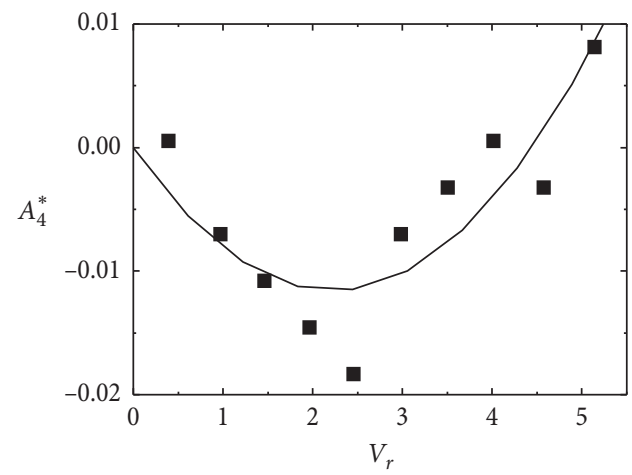

(h)

FIGURE 3: Fitting curves of flutter derivatives.

\section{The ELM and the Critical Flutter State}

3.1. The Equivalent Linearization Method (ELM). The equivalent linearization method (ELM) is a nonlinear solution based on the idea of the averaging method. The nonlinear system shows the characteristics of approximate harmonics so, here, it mainly analyzes the first-order harmonics in the system motion and transforms the nonlinear system into an equivalent linear system composed of various equivalent parameters (mass, damping, and stiffness). Then, the linear solution method was used to discuss the nonlinear system.

According to the calculation method [45], nonlinear equation (2) of the flutter system is written as follows:

$$
I \ddot{\alpha}+I \omega_{\alpha}^{2} \alpha+f(\dot{\alpha}, \alpha)=0,
$$

where $f(\alpha, \dot{\alpha})$ is the sum of all terms except inertial force and linear elastic force; it includes the damping and cubic nonlinear stiffness in the nonlinear equation, and here, it contains nonlinear damping, but it is not considered in this article. Then, expand $f(\alpha, \dot{\alpha})$ into Fourier series:

$$
f(\dot{\alpha}, \alpha)=r_{0}+\sum_{n=1}^{\infty}\left(s_{n} \cos n \varphi+t_{n} \sin n \varphi\right), \quad n=1,2,3, \ldots
$$

When fluttering, the ELM assumes that the first-order harmonic force has made a majority in vibration, therefore the first-order harmonic force is retained. The first-order coefficients of Fourier series expansion are as follows:

$$
\begin{aligned}
& r_{0}=\frac{1}{2 \pi} \int_{0}^{2 \pi} f(\dot{\alpha}, \alpha) \mathrm{d} \varphi, \\
& s_{1}=\frac{1}{\pi} \int_{0}^{2 \pi} f(\dot{\alpha}, \alpha) \cos \varphi \mathrm{d} \varphi \\
& t_{1}=\frac{1}{\pi} \int_{0}^{2 \pi} f(\dot{\alpha}, \alpha) \sin \varphi \mathrm{d} \varphi .
\end{aligned}
$$

The nonlinear equation can be denoted with the equivalent linearized equation as follows:

$$
I_{e} \ddot{\alpha}+c_{e} \dot{\alpha}+k_{e} \alpha=0 .
$$

And, suppose that the solution of equivalent linearized equation (11) is

$$
\alpha=A \cos \left(\omega_{e} t+\theta\right)=A \cos \varphi
$$

Among them, $\omega_{e}$ is the vibration frequency and $A$ is the amplitude of equivalent linearized equation (11). Hypothetical solution (12) and first-order Fourier series (9) of $f(\dot{\alpha}, \alpha)$ are substituted into nonlinear equation (8); then, equation (8) is organized into the form of equivalent linear equation (11) and written in the following equation: 


$$
I \ddot{\alpha}+\left[-\frac{1}{\pi a \omega_{e}} \int_{0}^{2 \pi} f(\dot{\alpha}, \alpha) \sin \varphi \mathrm{d} \varphi\right] \dot{\alpha}+\left[I \omega_{\alpha}^{2}+\frac{1}{\pi a} \int_{0}^{2 \pi} f(\dot{a}, \alpha) \cos \varphi \mathrm{d} \varphi\right] \alpha=0 .
$$

In this article, damping is expressed linearly so that the equivalent calculation of cubic nonlinear stiffness is adopted. And, the equivalent linear stiffness coefficient is obtained by the following calculation method:

$$
k_{\alpha e q}=k_{e}=I \omega_{\alpha}^{2}+\frac{1}{\pi a} \int_{0}^{2 \pi} f(\alpha, \dot{\alpha}) \cos \varphi \mathrm{d} \varphi .
$$

Among them, $f(\dot{\alpha}, \alpha)$ contains the cubic nonlinear stiffness. Assuming that when flutter occurs, the simple harmonic vibration amplitude of the torsional freedom is $A$, so the equivalent stiffness coefficient is calculated as follows:

$$
k_{\alpha e q}=I \omega_{\alpha}^{2}+\frac{3}{4} e_{\alpha} A^{2},
$$

where $k_{\alpha e q}$ becomes the function of $A$ which is the amplitude of the torsional degree.

For the convenience of calculation and expression, let

$$
k_{\text {heq }}=m_{h} \omega_{h}^{2} \text {. }
$$

The nonlinear torsional stiffness $I \omega_{\alpha}^{2} \alpha+e_{\alpha} \alpha^{3}$ and vertical stiffness $m_{h} \omega_{h}^{2} h$ in flutter equations (1) and (2) are substituted by the equivalent linearized stiffness coefficients $k_{\alpha e q} \alpha$ and $k_{\text {heq }} h$ :

$$
\begin{aligned}
m_{h} \ddot{h}+2 \xi_{h} m_{h} \omega_{h} \dot{h}+k_{h e q} h & =\rho U^{2} B\left[K H_{1}^{*} \frac{\dot{h}}{U}+K H_{2}^{*} \frac{B \dot{\alpha}}{U}+K^{2} H_{3}^{*} \alpha+K^{2} H_{4}^{*} \frac{h}{B}\right], \\
I \ddot{\alpha}+2 \xi_{\alpha} I \omega_{\alpha} \dot{\alpha}+k_{\alpha e q} \alpha & =\rho U^{2} B^{2}\left[K A_{1}^{*} \frac{\dot{h}}{U}+K A_{2}^{*} \frac{B \dot{\alpha}}{U}+K^{2} A_{3}^{*} \alpha+K^{2} A_{4}^{*} \frac{h}{B}\right] .
\end{aligned}
$$

These are the equivalent linearized equations.

3.2. The Critical Flutter State. Assuming that when the nonlinear flutter system bifurcates in the critical state, the system vibrates in harmonic motion, and its limit cycle oscillation solution can be written as follows:

$$
\begin{aligned}
& h=H e^{i \omega t}, \\
& \alpha=A e^{i \omega t},
\end{aligned}
$$

where $H$ and $A$ are amplitudes of the vertical and torsional degree, respectively.

Then, these defined solutions are substituted into equivalent linearized equations (17) and (18), then expand reduced frequency $K=B \omega / U$, and divide $e^{i \omega t}$ :

$$
\begin{aligned}
-\omega^{2} H m_{h}+2 \xi_{h} m_{h} \omega_{h} \omega H i+k_{h e q} H & =\left[\rho B^{2} H_{1}^{*} H \omega^{2} i+\rho B^{3} H_{2}^{*} A \omega^{2} i+\rho B^{3} H_{3}^{*} A \omega^{2}+\rho B^{2} H_{4}^{*} H \omega^{2}\right], \\
-\omega^{2} A I+2 \xi_{\alpha} I \omega_{\alpha} \omega A i+k_{\alpha e q} A & =\left[\rho B^{3} A_{1}^{*} H \omega^{2} i+\rho B^{4} A_{2}^{*} A \omega^{2} i+\rho B^{4} A_{3}^{*} A \omega^{2}+\rho B^{3} A_{4}^{*} H \omega^{2}\right] .
\end{aligned}
$$


In addition, packing like terms, $H$ and $A$, these equations can be written as homogeneous equations:

$$
\begin{array}{r}
{\left[-\omega^{2} m_{h}+2 \xi_{h} m_{h} \omega_{h} \omega i+k_{h e q}-\rho B^{2} H_{1}^{*} \omega^{2} i-\rho B^{2} H_{4}^{*} \omega^{2}\right] H+\left[-\rho B^{3} H_{2}^{*} \omega^{2} i-\rho B^{3} H_{3}^{*} \omega^{2}\right] A=0,} \\
{\left[-\rho B^{3} A_{1}^{*} \omega^{2} i-\rho B^{3} A_{4}^{*} \omega^{2}\right] H+\left[-\omega^{2} I+2 \xi_{\alpha} I \omega_{\alpha} \omega i+k_{\alpha e q}-\rho B^{4} A_{2}^{*} \omega^{2} i-\rho B^{4} A_{3}^{*} \omega^{2}\right] A=0,}
\end{array}
$$

which can be written as matrix multiplication simplified: $\quad$ in which $\left(\begin{array}{ll}H_{1} & A_{1} \\ H_{2} & A_{2}\end{array}\right)$ is

$$
\left(\begin{array}{ll}
H_{1} & A_{1} \\
H_{2} & A_{2}
\end{array}\right)\left(\begin{array}{c}
H \\
A
\end{array}\right)=0
$$

$$
\left(\begin{array}{c}
-\omega^{2} m_{h}+2 \xi_{h} m_{h} \omega_{h} \omega i+k_{h e q}-\rho B^{2} H_{1}^{*} \omega^{2} i-\rho B^{2} H_{4}^{*} \omega^{2} \\
-\rho B^{3} A_{1}^{*} \omega^{2} i-\rho B^{3} A_{4}^{*} \omega^{2}
\end{array}\right.
$$

When the coefficient determinant $\left|\begin{array}{ll}H_{1} & A_{1} \\ H_{2} & A_{2}\end{array}\right|=0$, there is a nonzero solution to the homogeneous equation system, and the amplitudes $H$ and $A$ are not zero at this time. It is considered that the bridge system begins to flutter.

So, the coefficient determinant is expanded into an equation for $\omega$ that includes real and imaginary numbers:

$$
F(\omega)=f_{R}(\omega)+f_{I}(\omega) i=0 .
$$

The real and imaginary terms in expansion equation (25) are arranged into the real part equation $f_{R}(\omega)$ and imaginary part equation $f_{I}(\omega)$ :

$$
\begin{gathered}
-\rho B^{3} H_{2}^{*} \omega^{2} i-\rho B^{3} H_{3}^{*} \omega^{2} \\
\left.-\omega^{2} I+2 \xi_{\alpha} I \omega_{\alpha} \omega i+k_{\alpha e q}-\rho B^{4} A_{2}^{*} \omega^{2} i-\rho B^{4} A_{3}^{*} \omega^{2}\right) . \\
f_{R}(\omega)=R_{4} \omega^{4}+R_{3} \omega^{3}+R_{2} \omega^{2}+R_{1} \omega+R_{0}=0, \\
f_{I}(\omega)=I_{3} \omega^{3}+I_{2} \omega^{2}+I_{1} \omega+I_{0}=0 .
\end{gathered}
$$

These two equations are quartic equations, and their roots have to be $\omega \neq 0$. Therefore, the imaginary part equation has no constant term and can be written as cubic equation (27).

The coefficients of real and imaginary part equations are written as follows:

$$
\begin{aligned}
& R_{4}=\operatorname{Im}_{h}+\rho I B^{2} H_{4}^{*}+\rho m_{h} B^{4} A_{3}^{*}+\rho^{2} B^{6} A_{3}^{*} H_{4}^{*}-\rho^{2} B^{6} A_{4}^{*} H_{3}^{*}+\rho^{2} B^{6} A_{1}^{*} H_{2}^{*}-\rho^{2} B^{6} A_{2}^{*} H_{1}^{*} \\
& R_{3}=2 \rho B^{2} I \xi_{\alpha} \omega_{\alpha} H_{1}^{*}+2 \rho B^{4} m_{h} \xi_{h} \omega_{h} A_{2}^{*} \\
& R_{2}=-I k_{h e q}-m_{h} k_{\alpha e q}-\rho B^{4} k_{h e q} A_{3}^{*}-\rho B^{2} k_{\alpha e q} H_{4}^{*}-4 \operatorname{Im}_{h} \xi_{h} \xi_{\alpha} \omega_{h} \omega_{\alpha} \\
& R_{1}=0 \\
& R_{0}=k_{h e q} k_{\alpha e q} \\
& I_{3}=\rho I B^{2} H_{1}^{*}+\rho m_{h} B^{4} A_{2}^{*}-\rho^{2} B^{6} A_{1}^{*} H_{3}^{*}+\rho^{2} B^{6} A_{3}^{*} H_{1}^{*}+\rho^{2} B^{6} A_{2}^{*} H_{4}^{*}-\rho^{2} B^{6} A_{4}^{*} H_{2}^{*} \\
& I_{2}=-2 m_{h} I \omega_{h} \xi_{h}-2 m_{h} I \omega_{\alpha} \xi_{\alpha}-2 \rho I B^{4} \omega_{\alpha} \xi_{\alpha} H_{4}^{*}-2 \rho m_{h} B^{4} \omega_{h} \xi_{h} A_{3}^{*}, \\
& I_{1}=\rho B^{4} k_{h e q} A_{2}^{*}-\rho B^{2} k_{\alpha e q} H_{1}^{*} \\
& I_{0}=2 k_{h e q} I \omega_{\alpha} \xi_{\alpha}+2 k_{\alpha e q} m_{h} \omega_{h} \xi_{h} .
\end{aligned}
$$




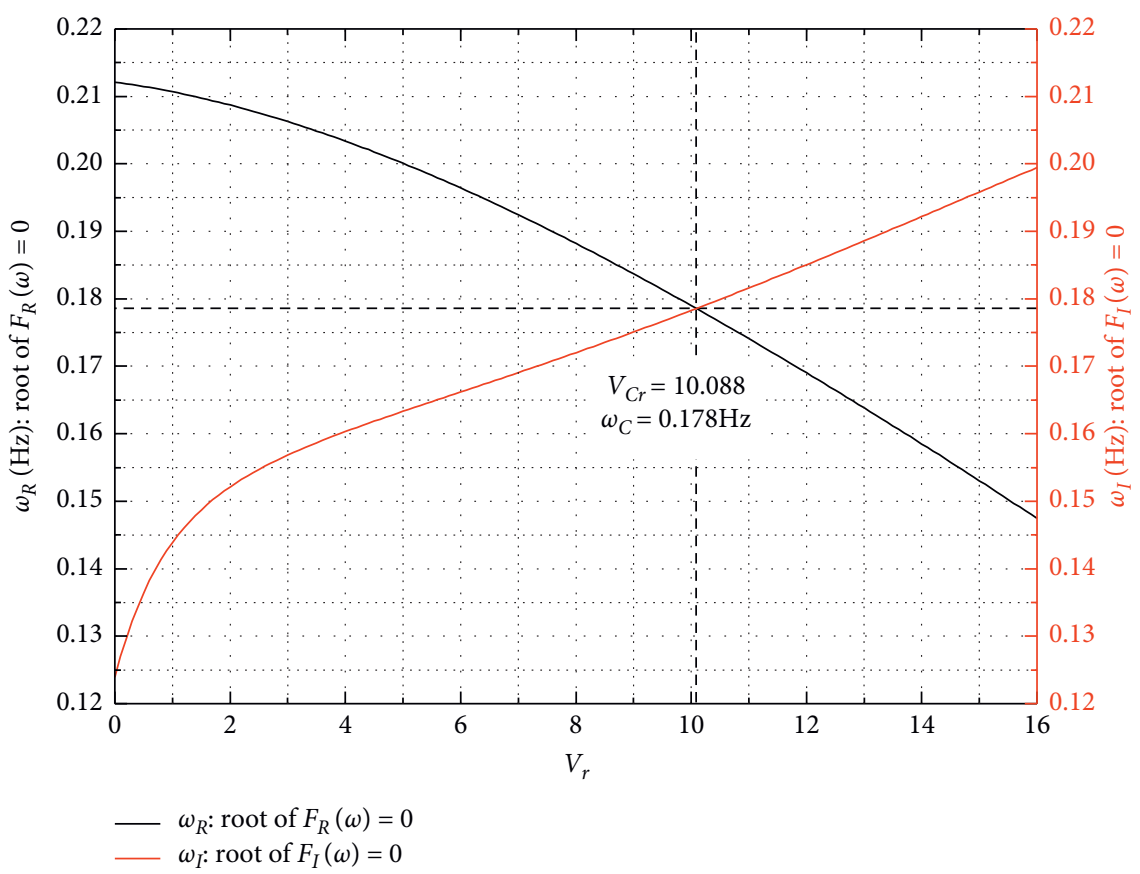

FIgURE 4: The intersection of the real part root and imaginary part root.

In this section, the method to solve equivalent linearized equations (17) and (18) is discussed in which the equivalent stiffness coefficients $k_{\text {heq }}$ and $k_{\alpha e q}$ are assumed as constant temporarily.

In coefficient matrix (24), it contains the unknown $\omega$ and eight flutter derivatives $H_{i}^{*}$ and $A_{i}^{*}(i=1,2,3$, and 4$)$. Since flutter derivatives $H_{i}^{*}$ and $A_{i}^{*}$ are functions of reduced wind speed $V_{r}$, expanding equation (25) or real and imaginary part equations (26) and (27) can be regarded as functions of the independent variable $\omega$ which includes parameter $V_{r}$.

In order to find the solution of equations (26) and (27), the following calculation process is required.

To do a cycle solving progress, first, a reduced wind speed value is set to obtain eight flutter derivatives and make the real and imaginary part equations only $\omega$ unknown. Then, the positive roots $\omega_{R}$ and $\omega_{I}$ can be obtained by solving the two equations, respectively. By increasing the reduced wind speed value from zero gradually, several sets of solutions $\omega_{R}$ and $\omega_{I}$ related to the reduced wind speed can be obtained. Next, the solutions are drawn on the grid in Figure 4; the value of reduced wind speed as abscissa and the value of $\omega_{R}$ and $\omega_{I}$ as ordinate. Then, all the dots of $\omega_{R}$ and $\omega_{I}$ are connected to be two lines, and they intersected at a point, which means that the real and imaginary part equations have a same solution; the frequency is $\omega_{C}=\omega_{R}=\omega_{I}$, and the reduced wind speed is $V_{C r}=V_{r}$. So, when $V_{r}=V_{C r}, \omega=\omega_{C}$ is the solution of expanding equation (25). Finally, $V_{c r}$ and $\omega_{c}$ are substituted into the coefficient matrix of homogeneous equations (21) and (22); the ratio of vertical to torsional amplitude, $H / A$, is obtained. In this case, the coefficient determinant equals to zero, and the solutions $H$ and $A$ of homogeneous equations are not equal to zero. It was the solution of the equivalent linearized flutter equations.
About the intersection point, the value of abscissa is the critical flutter reduced wind speed $V_{C r}=10.088$, and the value of ordinate is the critical flutter vibration frequency $\omega_{C}=0.178$. Then, the critical flutter wind speed has been calculated that $U=75.114$ according to $V_{r}=U / B \omega$, and the vertical-torsional ratio is $H / A=9.443$, that is, the critical state of the flutter system in this paper. In other words, when the wind speed is $75.114 \mathrm{~m} / \mathrm{s}$, the suspension bridge will flutter and be instable to bifurcate, and its frequency of vibration is $\omega=0.178$, and its torsional-vertical ratio is $H / A=9.443$.

3.3. Solution of Equivalent Linearization Equations. In this section, the equivalent stiffness coefficients $k_{h e q}$ and $k_{\alpha e q}$ in equations (15) and (16) will be taken into account in the solution process because the coefficient $k_{\alpha e q}$ is the function of torsional amplitude $A$.

First, a torsional amplitude $A$ is the limit cycle amplitude of the system when the flutter occurs is assumed, so the equivalent stiffness coefficient $k_{\alpha e q}$ is determined; the following calculation steps are the same as in Section3.2.

The critical flutter solutions including reduced wind speed $V_{C r}$, frequency $\omega_{C}$, wind speed $U_{C}$, vertical-torsional ration $H / A$, and vertical amplitude $H$ can be all obtained. So, these solutions can be interpreted as that the nonlinear flutter system will cause limit cycle oscillation (LCO) when the wind speed is $U_{C}$. The vertical and torsional amplitude of limit cycle oscillation are $H$ and $A$, respectively, and the frequency of vibration is $\omega_{C}$.

Based on the above analysis and calculation, the characteristic curves of the nonlinear flutter system are drawn in Figures 5-8. In order to validate the equivalent linearization method (ELM), numerical solutions by using the 


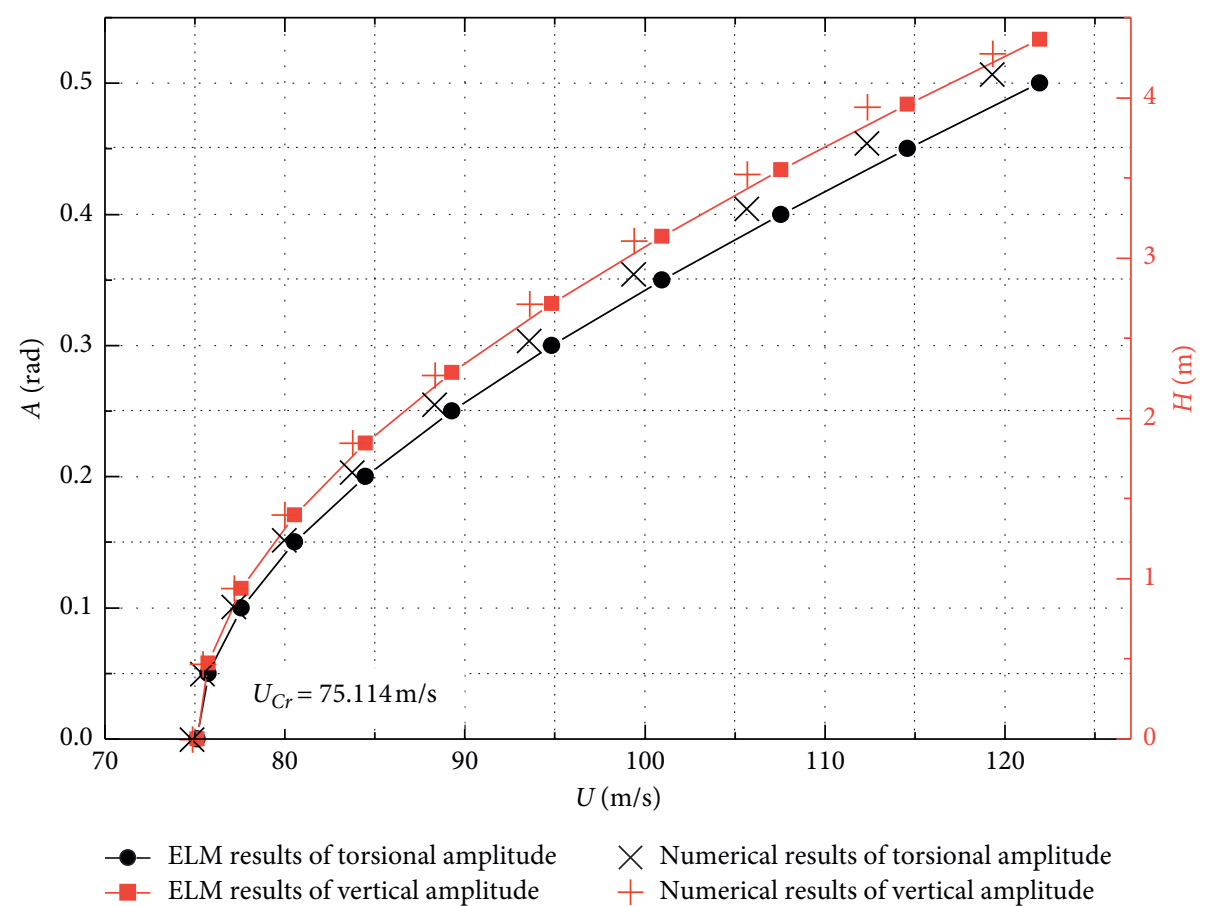

FIGURE 5: Curve of wind speed and amplitudes of LCOs.

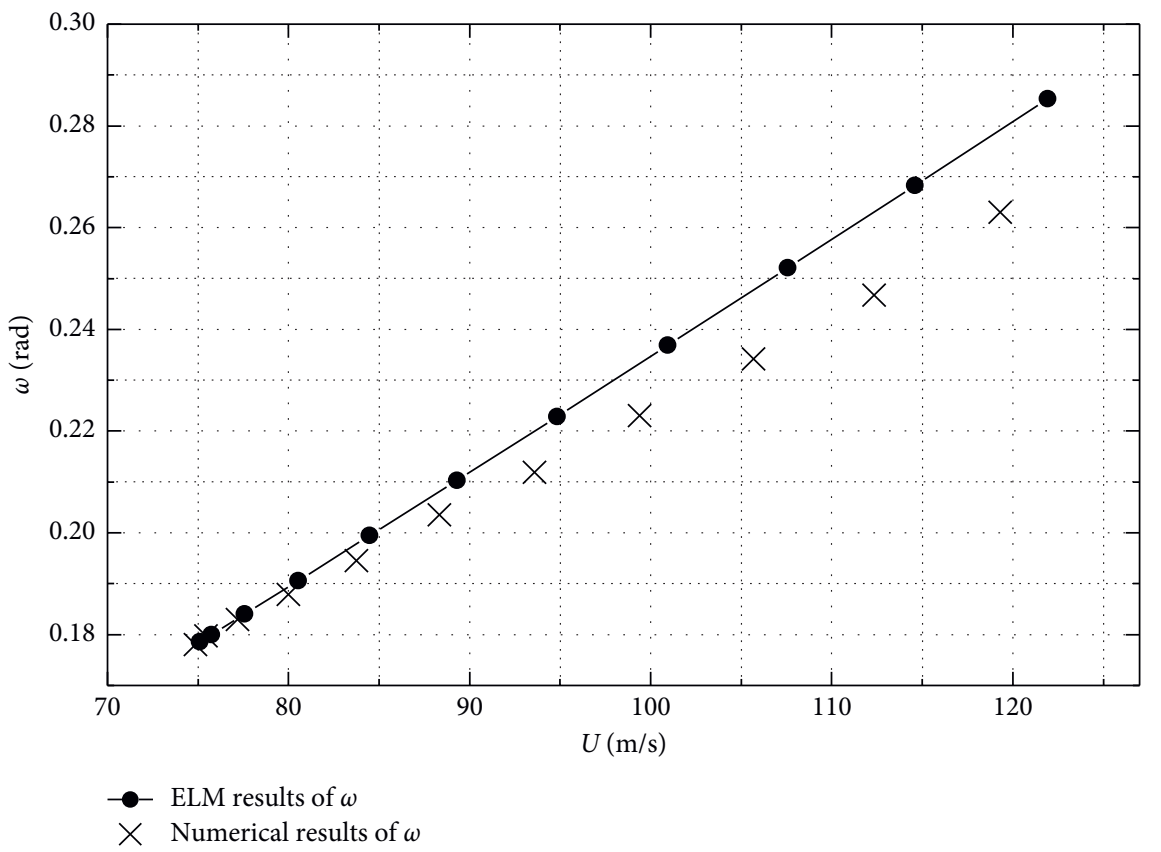

Figure 6: Curve of wind speed and frequency of LCOs.

Runge-Kutta method [46, 47] are obtained, whose results are shown in Figures 5-8 too.

As shown in Figure 5, the values of wind speed $U$ are taken as abscissa, and the values of vertical and torsional amplitudes are taken as ordinate; then, the same, as in the abovementioned paragraph, two curves in the grid can be obtained. The nonlinear system has flutter instability when critical flutter wind speed is $U_{C}=75.114 \mathrm{~m} / \mathrm{s}$ and system bifurcates to LCOs at the same time. Beyond the critical flutter wind speed, the amplitude of LCOs in vertical and torsional degrees increases monotonously when the wind speed is increasing. Also, the solution by ELM agrees well with the numerical results by the Runge-Kutta method.

As shown in Figure 6, the values of wind speed $U$ are taken as abscissa, and the values of flutter LCOs' frequency $\omega$ 


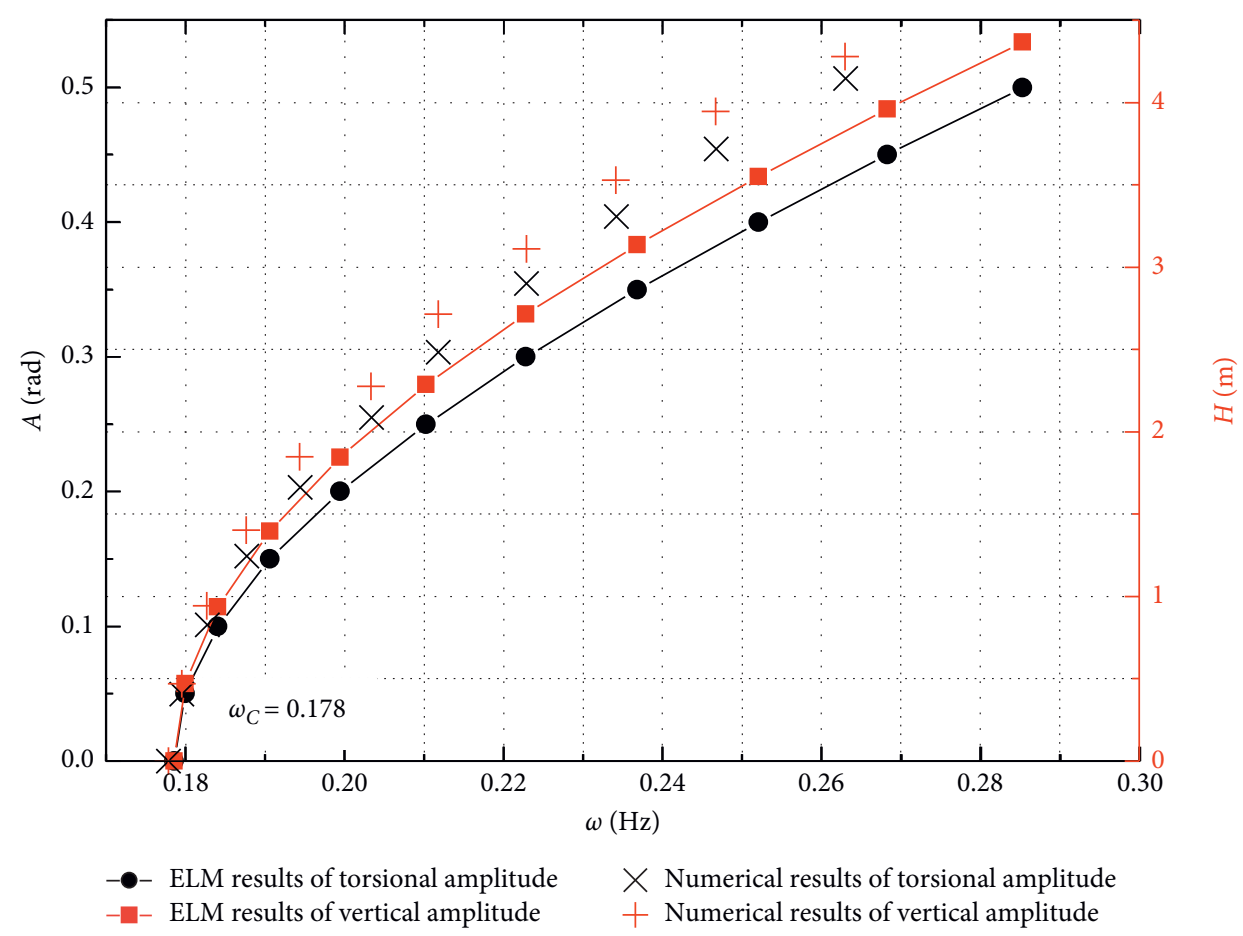

FIgURE 7: Curve of frequency and amplitudes of LCOs.

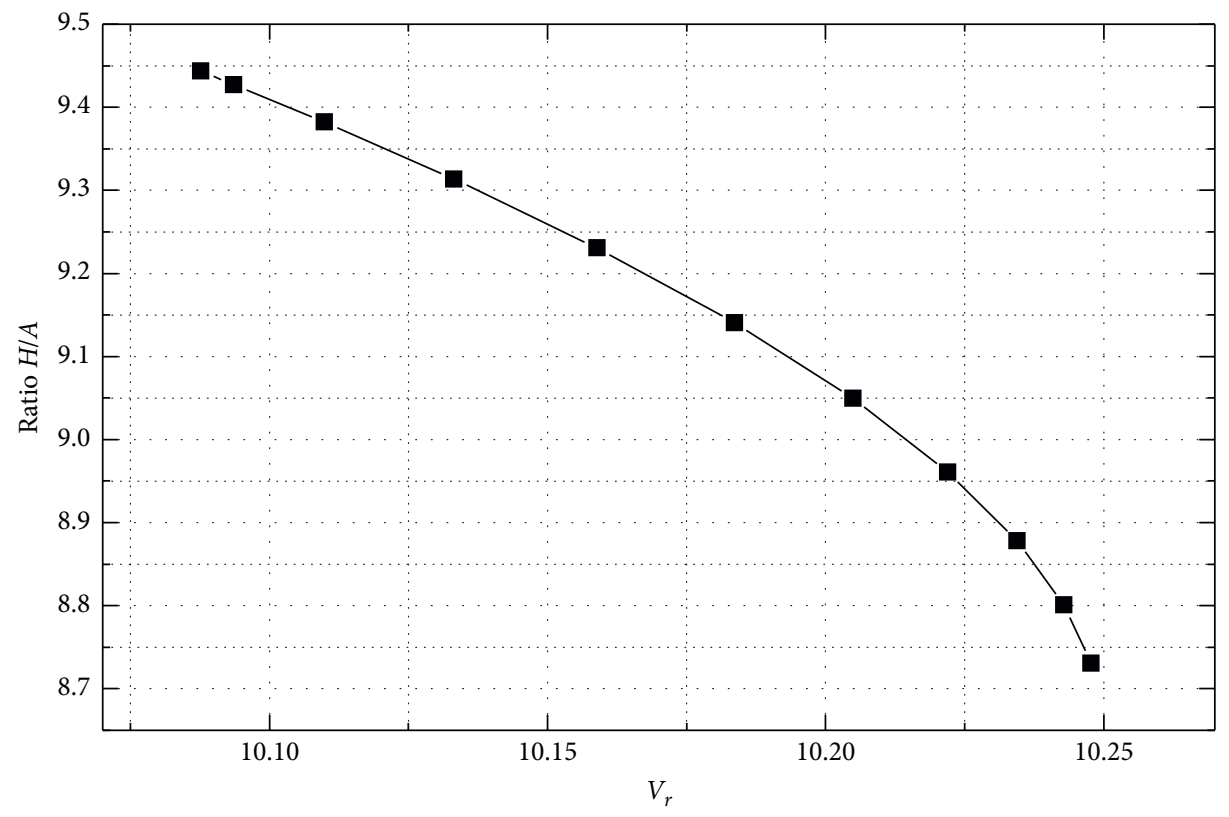

ELM results of $H / A$

FIGURE 8: Curve of reduced wind speed and vertical-torsional ratio.

are taken as ordinate, and the nonlinear system reaches the critical state of flutter at wind speed $U_{C}=75.114 \mathrm{~m} / \mathrm{s}$, and the critical frequency of flutter is $\omega_{C}=0.1786$. Then, the limit cycle frequency increases monotonically with the wind speed after the bifurcation. Compared with the numerical solution of the Runge-Kutta method at the " $x$ " point in the figure, the frequency of the limit cycle oscillation obtained by the ELM is the larger one.

As shown in Figure 7, the values of flutter LCOs' frequency $\omega$ are taken as abscissa, and the values of vertical and torsional amplitudes are taken as ordinate; then, two curves are lined through dots of the vertical and torsional degree, 


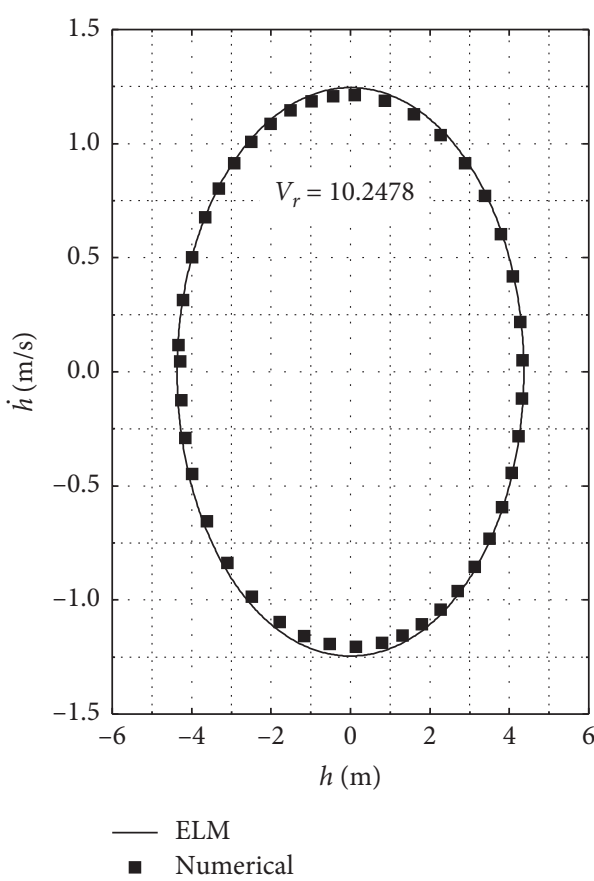

(a)

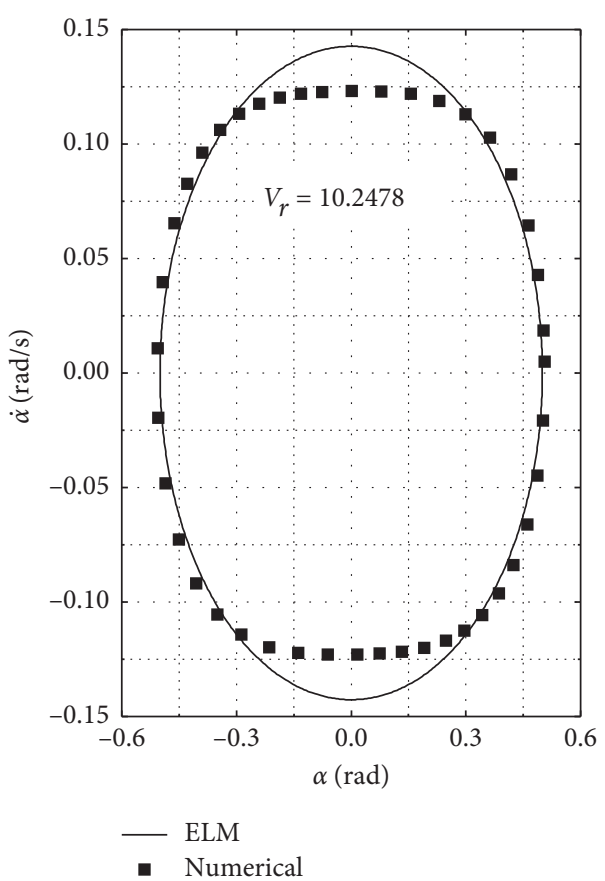

(b)

Figure 9: Limit cycle oscillation (LCO) vs. numerical solutions. (a) LCO in the vertical degree. (b) LCO in the torsional degree.

respectively, in the grid. The frequency of the LCO of the nonlinear system at the bifurcation point is the critical frequency $\omega_{C}=0.178$. Beyond the critical flutter value, the amplitude of LCOs in vertical and torsional degrees increases monotonously with increasing frequency of LCOs. And, it is that the numerical results are slightly larger than the solutions by ELM.

As shown in Figure 8, the values of reduced wind speed are taken as abscissa, and the values of the vertical-torsional ratio are taken as ordinate; one curve is lined through the solid square dots. The nonlinear system has flutter instability when critical flutter reduced wind speed $V_{C r}=10.088$. The vertical-torsional ratio of LCOs decreases monotonously with reduced wind speed.

Finally, to validate the feasibility of ELM, the vertical amplitude, torsional amplitudes, and frequency, which at the reduced wind speed $V_{r}=10.248$, are substituted into the assumed solution $h=H e^{i \omega t}$ and $\alpha=A e^{i \omega t}$ in Section 3.3. Now, the LCO can be drawn into the phaser diagrams shown in Figure 9. The abscissa is the displacement of vertical and torsional degrees, and the ordinate is velocity of vertical and torsional degrees. The solid lines are solutions of ELM, and dots are numerical results. The comparisons show that the results of ELM and numerical method are very closed in the displacement phase, which indicated that the first-order harmonic is dominant in LCO and that the ELM considering the first-order harmonic is practicable. The LCO, which is assumed to be harmonic vibration, is very close to the numerical results. Compared with the LCO of the vertical and torsional degree, the LCO of the vertical degree is closer to the numerical results in displacement and velocity, and the velocity in LCO of the torsional degree is larger than the numerical results with an error of $16 \%$ which may be related to the removal of higher-order harmonic vibration in ELM.

Therefore, the flutter bifurcation problem of the nonlinear system can be analyzed by the calculation result of the ELM.

\section{Analysis of the Hopf Bifurcation}

Hopf bifurcation refers to the phenomenon that, as the system parameters change to exceed the critical value, the system suddenly moves flutter and periodic oscillation from a stable equilibrium state before. From the phase diagram, when beyond the critical flutter value, the stable focus of the system will suddenly appear as an isolated closed trajectory called limit cycle oscillation (LCO).

In the solution of the previous section, when the determinant of the flutter system is zero, the homogeneous equation has nonzero solutions. And, the flutter system is in a critical state, that is, when the system is slightly disturbed or exceeds the critical state, there will be a bifurcation and a nonzero solution will appear at this time.

In the vicinity of the flutter critical value, two reduced wind speed values are $V_{r}=10.0866$ and $V_{r}=10.0966$, and the flutter critical frequency $\omega_{C}=0.1786$ is selected; then, the LCOs are solved by using the Runge-Kutta method and are drawn on the phase diagram.

As shown in Figures 10(a) and 10(b), when the reduced wind speed is less than the critical value that $V_{r}=10.0866$, 


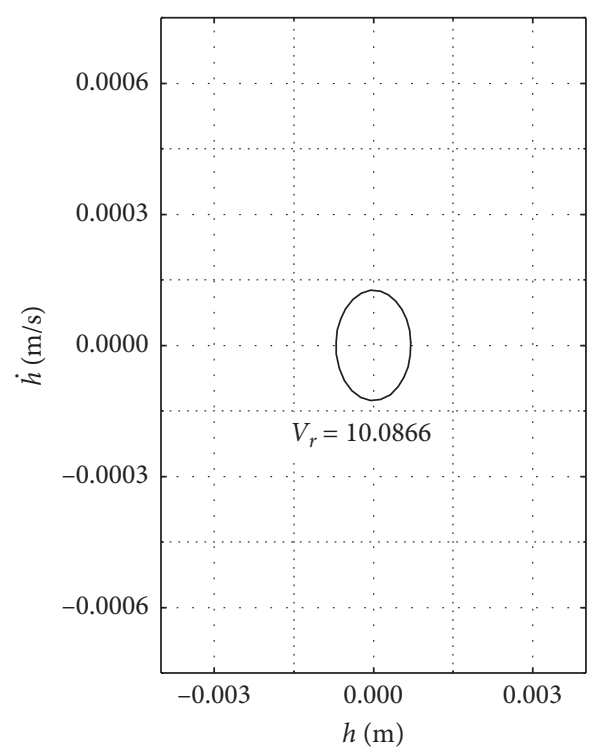

(a)

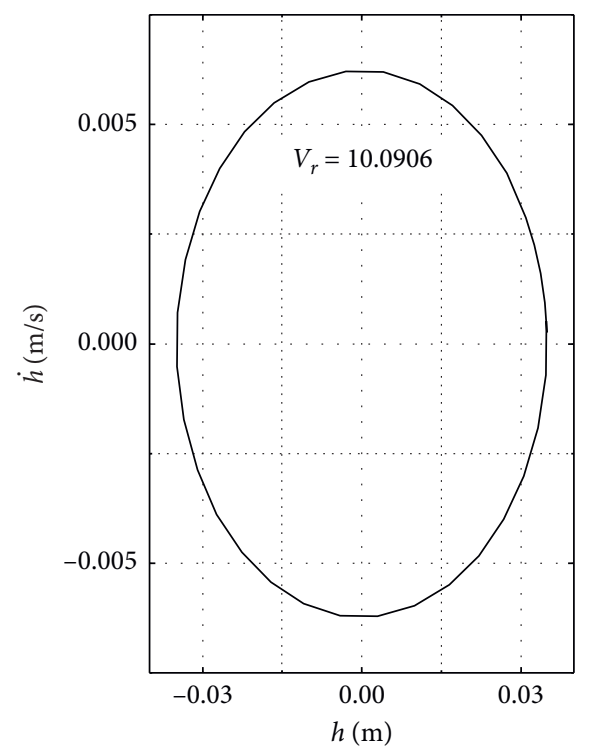

(c)

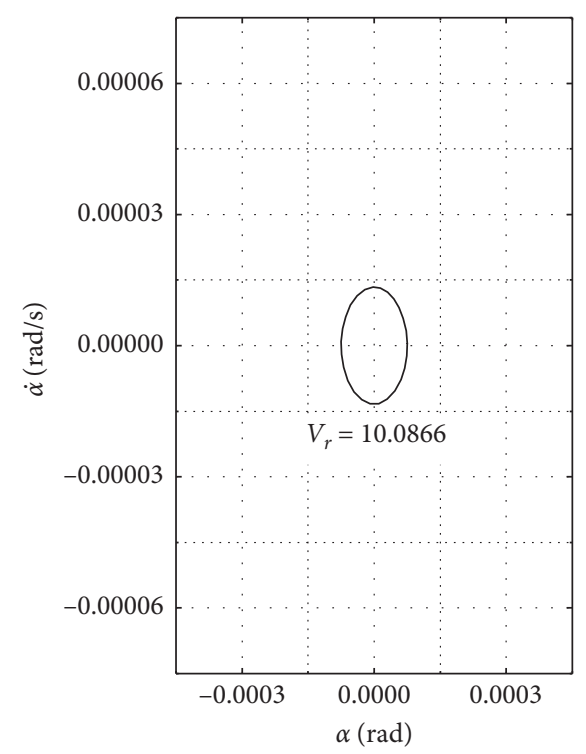

(b)

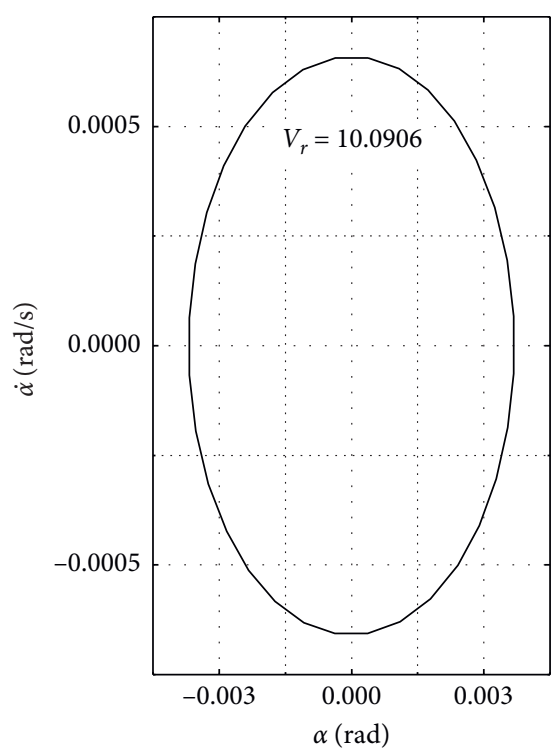

(d)

Figure 10: LCOs of two different reduced wind speed values. (a) LCO when $V_{r}=10.0866$. (b) LCO when $V_{r}=10.0866$. (c) LCO when $V_{r}=10.0906$. (d) LCO when $V_{r}=10.0906$.

TABLE 3: Values of the damping ratio in three conditions.

\begin{tabular}{lccc}
\hline & Condition 1 & Condition 2 & Condition 3 \\
\hline Vertical damping ratio $\xi_{h}$ & 0.005 & 0.005 & 0.003 \\
Torsional damping ratio $\xi_{\alpha}$ & 0.005 & 0.007 & 0.007 \\
\hline
\end{tabular}

the trajectory of the phase diagram has an amplitude of $5 \times 10^{-4}$, which can be regarded as a stable focus, and the system does not vibrate. When the reduced wind speed $V_{r}=10.0906$ that is higher than the critical value, results in Figures 10(c) and 10(d) show that vertical amplitude of LCO is 0.035 and that of the torsional amplitude is 0.0037 , which is a stable limited amplitude vibration, forming an isolated closed trajectory. When the parameter $V_{r}$ gradually increases, the nonlinear system bifurcates from the stable state to the LCO state. So, the bifurcation of the system in the critical state belongs to the supercritical Hopf bifurcation. 


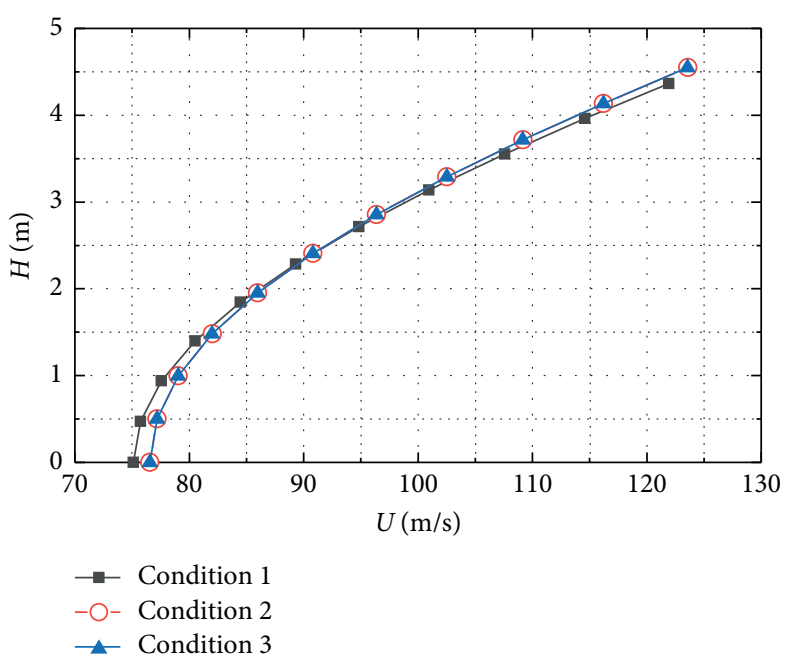

(a)

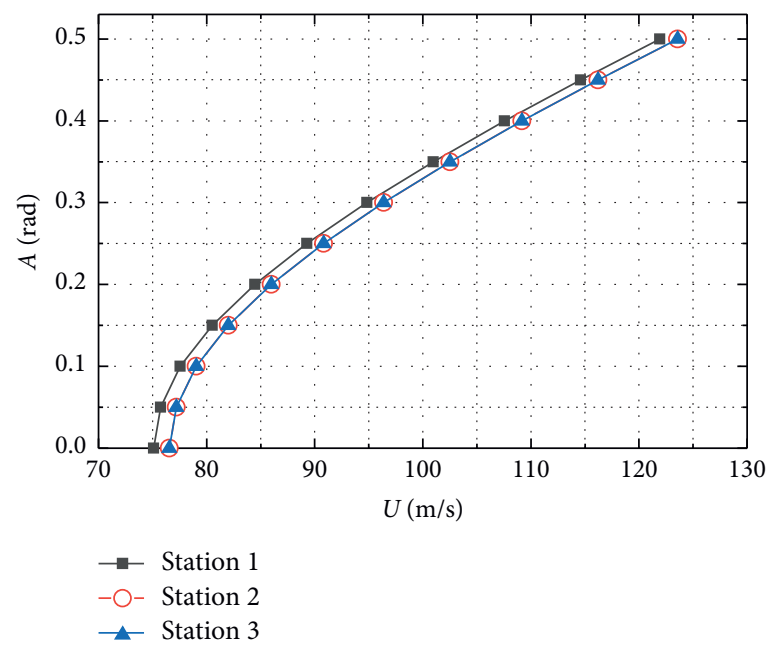

(b)

Figure 11: Curves of wind speed and amplitudes of LCOs in three conditions. (a) $U$ vs. $H$. (b) $U$ vs. $A$.

\section{Effect of Damping Ratio and Cubic Stiffness on Bifurcation and LCOs}

It is known from the previous section that a suspension bridge system with strong nonlinearity undergoes a supercritical Hopf bifurcation in the flutter critical state and has LCOs appeared on the right side, while the damping and nonlinear stiffness coefficients of the system may affect the bifurcation and LCOs. In this section, the effect of damping ratio and cubic stiffness on bifurcation and LCOs of the nonlinear system is taken into discussion. Based on the original bridge nonlinear flutter system, sets of damping ratios for vertical and torsional degrees and different cubic stiffness coefficients were set, respectively, to discuss the effects on bifurcation state and LCOs.

The damping ratio of a steel integral structure generally ranges from 0.003 to 0.007 , and it will change with service life and different construction conditions. Also, tuned mass dampers are usually installed to adjust the bridge damping ratio $[48,49]$. Therefore, by analyzing the effects on critical flutter state and LCOs when the bridge system damping ratio is changed, we can get the degree of freedom damping ratio change that has the greatest influence on bridge flutter.

Three working conditions are discussed, as shown in Table 3. Condition 1 is the damping ratio of the original bridge system. In condition 2 , the torsional damping ratio is increased by $40 \%$ to 0.007 on the basis of condition 1 , and the vertical damping ratio remains unchanged, and the effect of changing the torsional damping ratio is studied. In condition 3 , on the basis of case 2, the vertical damping ratio is reduced by $40 \%$ to 0.003 , and the torsional damping ratio remains unchanged. The effect of the vertical damping ratio is studied.

Using the ELM and solving the equivalent linearized equations in this paper, the bifurcation and LCOs can be calculated, and the results are shown as follows.

As shown in Figure 11, the nonlinear systems of the three conditions reach the critical state of flutter at wind speed
$U=75.1144, U=76.5683$, and $U=76.5602$, and bifurcation occurs. LCOs appear on vertical and torsion degrees simultaneously. Conditions 2 and 3 bifurcate later than condition 1, and their bifurcation curves almost coincide. The amplitude of the limit cycle of the three conditions changes with the increase of wind speed similarly. For the vertical degree, the amplitude of the LCO in the higher reduced wind speed of the bifurcation of condition 2 and condition 3 is slightly larger than that of condition 1 . As for the torsional degree, the amplitude of the limit cycle is always smaller than that of condition 1 when conditions 2 and 3 have the same wind speed.

In Figure 12, all three conditions were flutter bifurcation and their flutter critical frequency were $\omega=0.1768$, $\omega=0.1773$, and $\omega=0.1773$. When beyond the flutter critical state, their amplitudes of LCOs were increasing by the growing of wind speed and frequency. In both vertical and torsional degrees, the amplitudes of LCOs in first condition are larger than the other two.

As shown in Figure 13, at the moment of the bifurcation of the critical flutter state, the critical wind speed of conditions 2 and 3 is larger than condition 1. In addition, the critical flutter wind speed of condition 2 is slightly greater than that of condition 3, and the critical flutter frequency is smaller than condition 3. The wind speed and frequency relationship lines of conditions 2 and 3 almost coincide with each other. The frequency of LCO in all three conditions shows a linear increasing trend with the increases of wind speed.

As shown in Figure 14, among the three working conditions, after the bifurcation of the nonlinear system, the ratio of the amplitude of the LCO of the vertical to the torsional decreases as the reduced wind speed increases. The vertical-torsional ratio of condition 2 and working condition 3 is greater than that of working condition 1 and shows a trend of rapid decrease.

According to the above analysis, comparing conditions 1 and 2, which only changing the torsional damping ratio, have an obvious influence on the Hopf bifurcation point and 


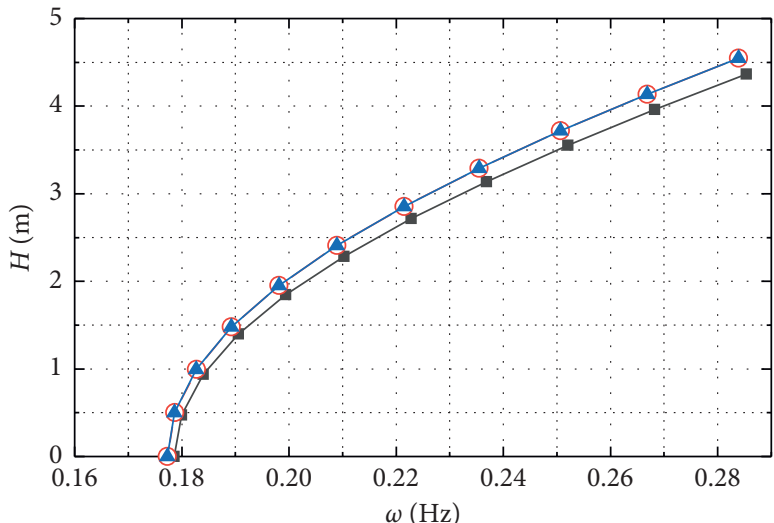

$\rightarrow$ Condition 1

-O- Condition 2

$\rightarrow$ Condition 3

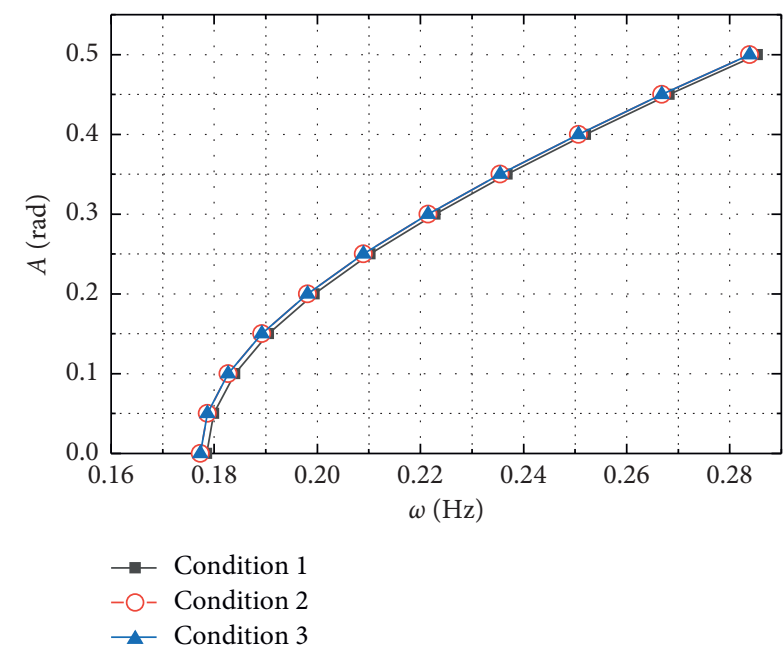

(b)

(a)

FIgURE 12: Curves of frequency and amplitudes of LCOs in three conditions. (a) $\omega$ vs. $H$. (b) $\omega$ vs. $A$.

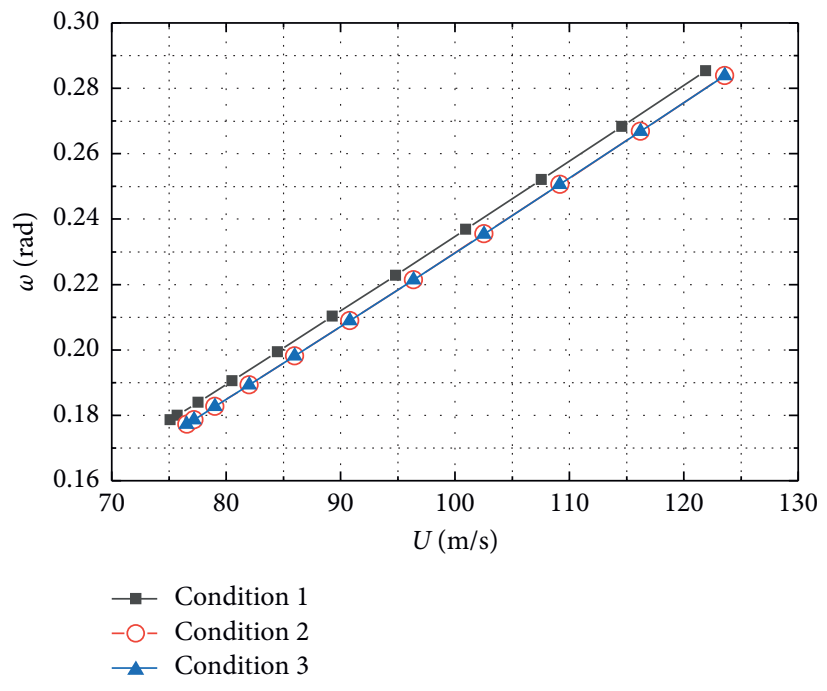

FIGURE 13: Curves of wind speed and frequency of LCOs in three conditions.

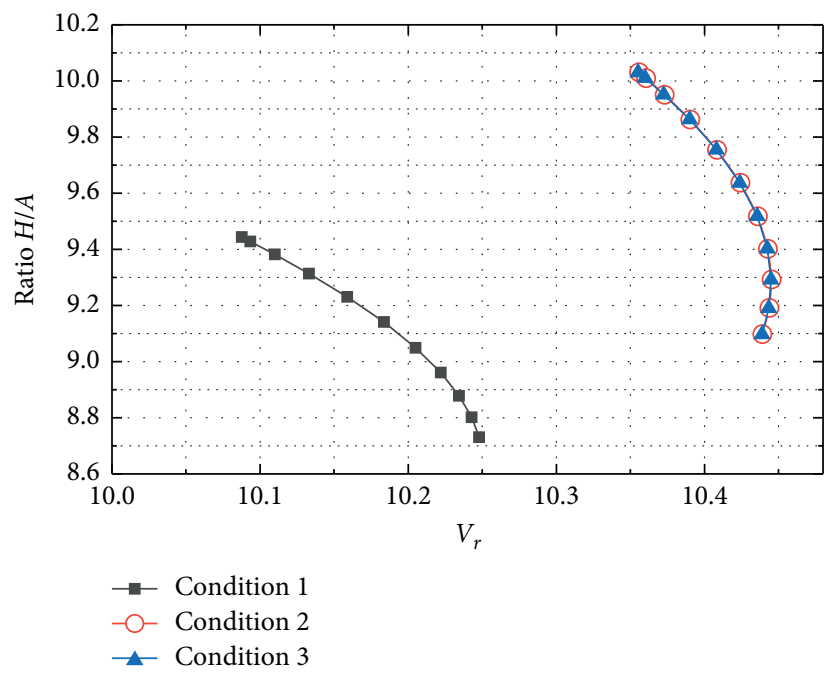

FIGURE 14: Curves of reduced wind speed and vertical-torsional ratio in three conditions. 


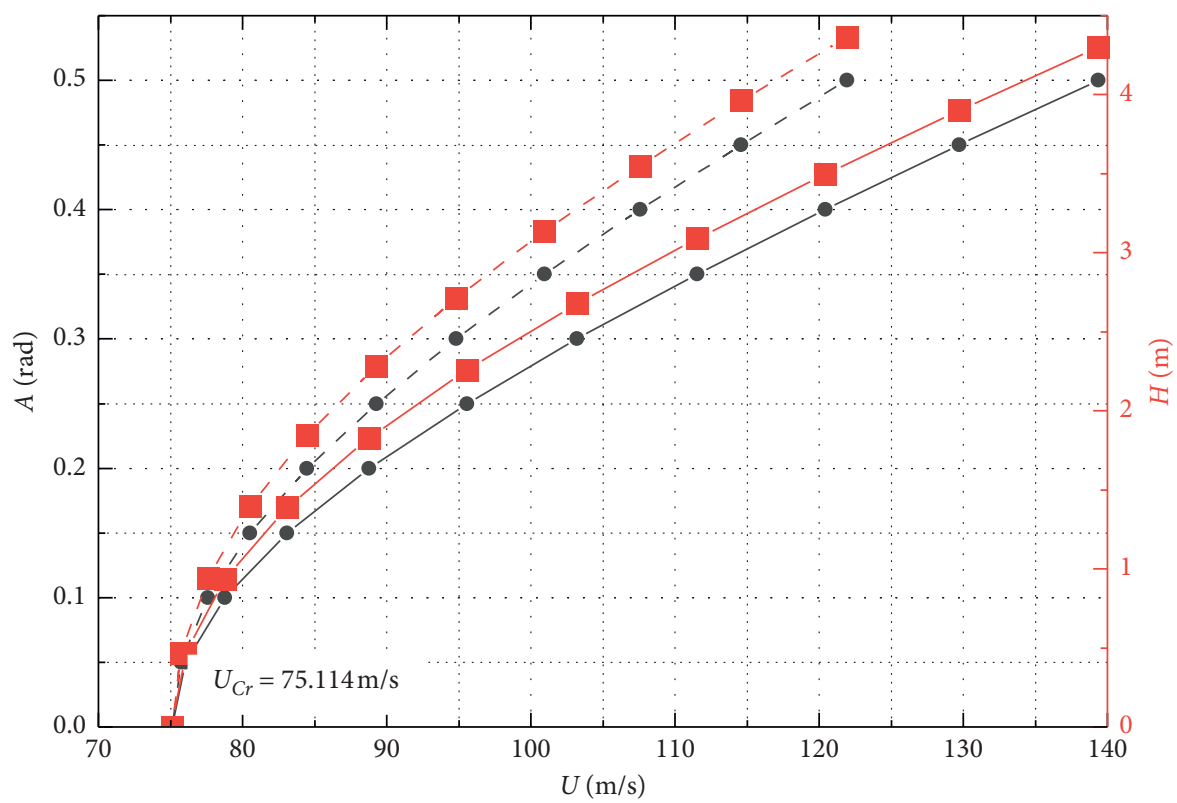

- - Torsional amplitude at initial cubic stiffness

Vertical amplitude at initial cubic stiffness

- - Torsional amplitude at 1.5 times cubic stiffness

Vertical amplitude at 1.5 times cubic stiffness

FIGURE 15: Curve of wind speed and amplitudes of LCOs.

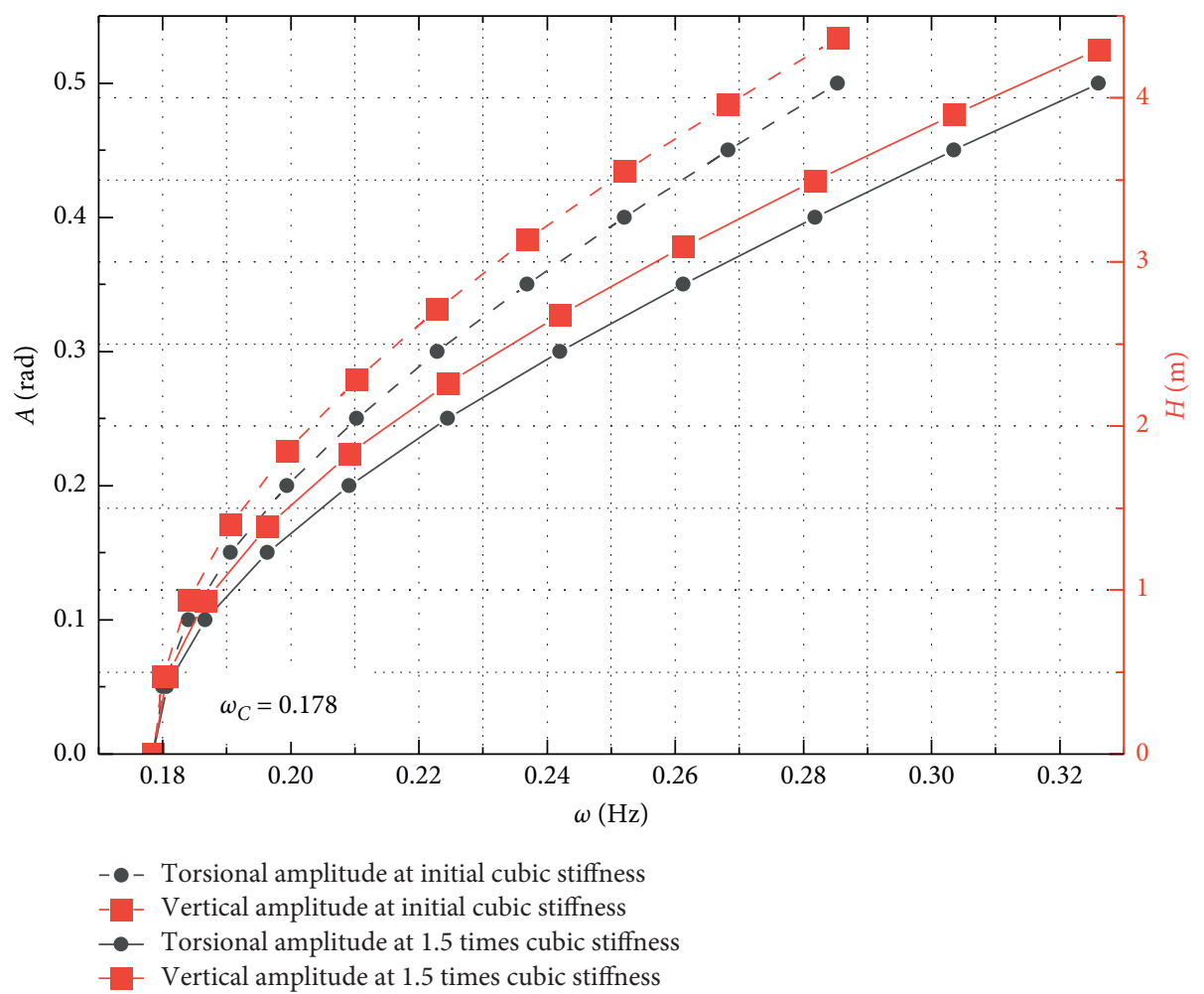

FIgURE 16: Curve of frequency and amplitudes of LCOs.

the LCOs after bifurcation of the nonlinear system. Increasing the torsional damping ratio, the Hopf bifurcation point of the nonlinear system, that is, the delay of the critical state, bifurcation occurs at a larger reduced wind speed and real wind speed. In the bifurcation critical state, the critical flutter frequency is smaller, and the amplitude and frequency 


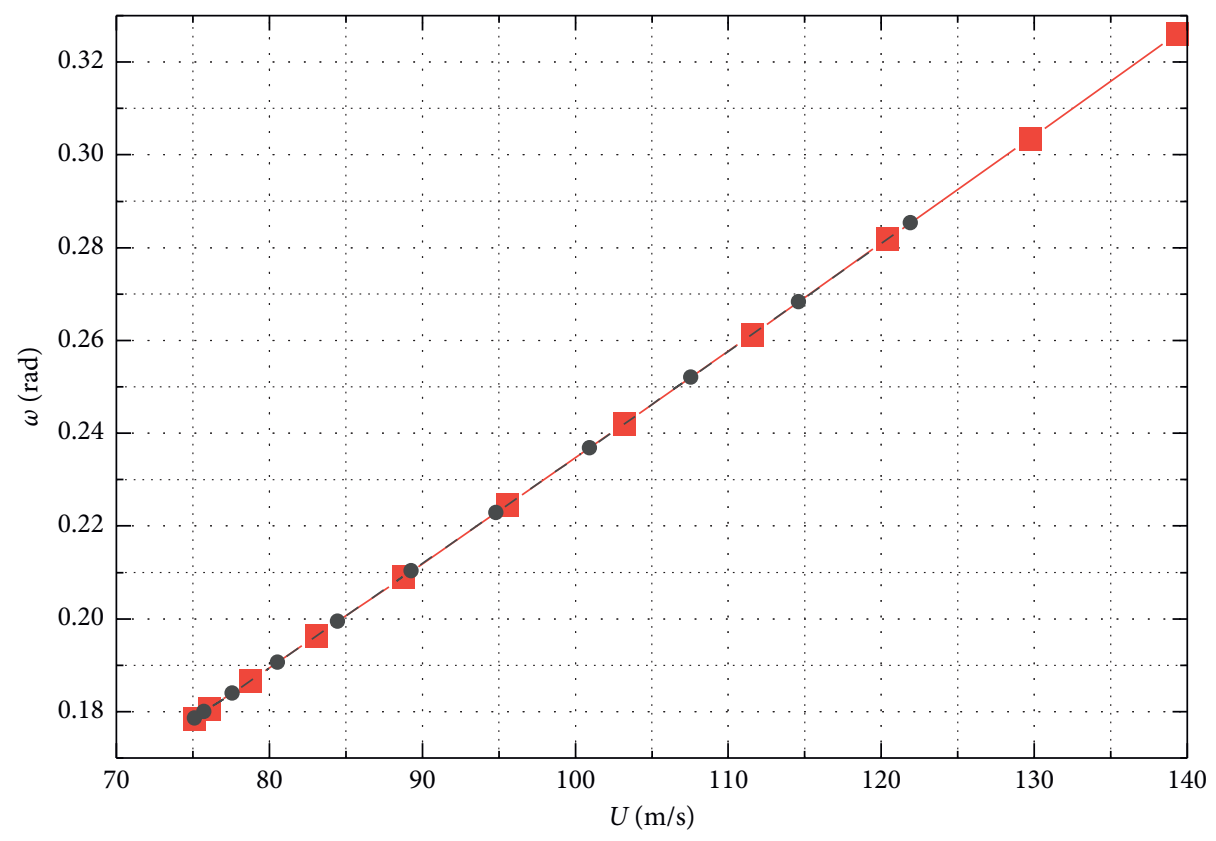

Frequency of LCOs at 1.5 times cubic stiffness

- Frequency of LCOs at initial cubic stiffness

FIgURE 17: Curve of wind speed and frequency of LCOs.

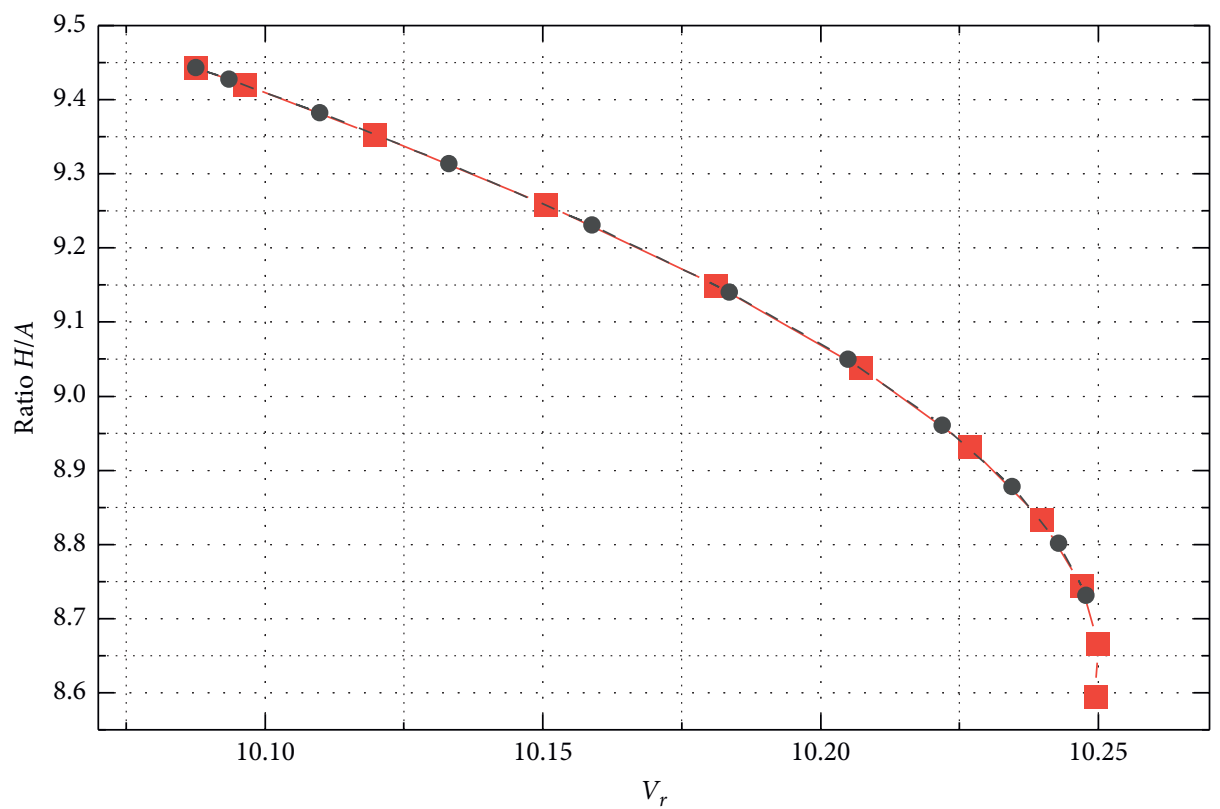

Ratio $H / A$ at initial cubic stiffness

- Ratio $H / A$ at 1.5 times cubic stiffness

FIgURE 18: Curve of reduced wind speed and vertical-torsional ratio.

of the LCOs are smaller after the bifurcation, and the vertical-torsional ratio of the LCOs amplitude is larger. Comparing conditions 2 and 3, which only changing the vertical damping ratio, have little effect on the Hopf bifurcation point and various parameters after bifurcation of the nonlinear system. If the torsional damping ratio of the suspension bridge decreases, the flutter critical wind speed will seriously reduce, but also the LCO amplitude of flutter will grow up.

Then, we discuss another set of comparisons, the influence of different cubic stiffness coefficients on the flutter bifurcation and limit cycles of the system. Assuming that the nonlinear stiffness coefficient of the bridge vibration system is set to 1.5 times the initial stiffness coefficient, that is, 
$e_{\alpha}=1500 m_{h} \omega_{\alpha}^{2}$, and called the "strong stiffness" system. The damping ratio of the vertical and torsional degree remains unchanged, that is, $\xi_{h}=0.005$ and $\xi_{\alpha}=0.005$; the calculation result is shown as the following figures. The dotted line is the initial system of the original system, and the solid line represents the "strong stiffness" system with 1.5 times the cubic stiffness coefficient.

As shown in Figures 15 and 16, both systems reach a critical state at the same time and flutter occurs. When the critical reduced wind speed $V_{C r}=10.088$ and the critical wind speed $U_{C r}=75.114 \mathrm{~m} / \mathrm{s}$, the system is in a critical state, the critical vibration frequency is $\omega_{C}=0.178 \mathrm{~Hz}$, and the limit cycle vibration appears. The amplitude of the limit cycle oscillation increases with the increase of reduced wind speed and real wind speed. As the amplitude increases, the vibration frequency also increases. The "strong stiffness" system is 1.5 times the cubic stiffness coefficient at the same reduced wind speed, wind speed, and frequency. The limit cycle oscillation amplitude is smaller than the initial basic system. It can be seen from Figures 15 and 16 that the "strong stiffness" system is at a higher wind speed and the vibration frequency is higher when the amplitude of the limit cycle of the two systems is same.

As shown in Figures 17 and 18, in the relationship between the wind speed vs. frequency of the limit cycle and the reduced wind speed vs. vertical-torsion ratio, the curves of the two systems coincide on the same line.

According to the above discussion of the two systems with different cubic stiffness coefficients, they both reach the critical state of flutter at the same wind speed value. The larger cubic stiffness coefficient has a positive aspect to the limit cycle vibration of the flutter system. In the same wind speed, its limit cycle oscillation amplitude is smaller. When the limit cycle vibration of the same amplitude occurs, the vibration frequency is higher. The relationship between limit cycle oscillation frequency and wind speed and verticaltorsion ratio and reduced wind speed has not changed.

\section{Results and Discussion}

In this paper, a bridge flutter model with cubic nonlinear stiffness was taken to study, which reflects the subject that the large-span characteristic of the Nizhou Waterway Bridge. The qualitative and quantitative flutter analysis for a long-span suspension bridge with strong nonlinearity in structural stiffness is carried out by an approximate analytical equivalent linearization method, revealing the limit cycle oscillation phenomena of bifurcation beyond the flutter critical state.

When the nonlinear flutter system reaches a critical state, a supercritical Hopf bifurcation occurs and LCOs are born to the right of the bifurcation point. This nonlinear flutter system will vibrate periodically with a certain amplitude and frequency at a certain wind speed beyond the critical speed. The amplitude and frequency of the vibration are increasing as wind speed grows up.

Also, analyzing the influence of structural factors on them, this provided a reference basis for wind resistance design of long-span suspension bridges. In particular, increasing the torsional damping ratio $\xi_{h}$ had effectively improven the critical flutter wind speed of the bridges. On the contrary, the decrease of the torsional damping ratio in a service bridge caused by structural factors change will seriously reduce the critical flutter wind speed. However, increasing the vertical damping ratio $\xi_{h}$ had little effect on the delay of the critical flutter state, the amplitude and frequency of LCOs after bifurcation, and the vertical-totorsion ratio, which is not so apparent as the change is brought about by the increase of the torsional damping ratio. At the same time, the use of structural measures to improve the torsional stiffness of the structure also had a positive effect. A larger cubic stiffness coefficient took a positive effect on the bridge flutter system although the critical state had no difference, but the vibration amplitude of the limit cycle oscillations at one wind speed was reduced. When the limit cycle oscillation occurs with the same amplitude, a system with a higher cubic stiffness coefficient had a higher vibration frequency.

\section{Data Availability}

The data used to support the findings of the study are available from the corresponding author upon request.

\section{Conflicts of Interest}

The authors declare that there are no conflicts of interest.

\section{Acknowledgments}

This study was supported by National Natural Science Foundation of China (11032005).

\section{References}

[1] R. H. Scanlan and J. J. Tomko, "Airfoil and bridge deck flutter derivatives," Journal of the Engineering Mechanics Division, vol. 97, no. 6, pp. 1717-1737, 1971.

[2] R. H. Scanlan, "The action of flexible bridges under wind, I: flutter theory," Journal of Sound and Vibration, vol. 60, no. 2, pp. 187-199, 1978.

[3] R. H. Scanlan, "The action of flexible bridges under wind, II: buffeting theory," Journal of Sound and Vibration, vol. 60, no. 2, pp. 201-211, 1978.

[4] M. Matsumoto, Y. Daito, F. Yoshizumi, Y. Ichikawa, and T. Yabutani, "Torsional flutter of bluff bodies," Journal of Wind Engineering and Industrial Aerodynamics, vol. 69-71, pp. 871-882, 1997.

[5] M. Matsumoto, F. Yoshizumi, T. Yabutani, K. Abe, and N. Nakajima, "Flutter stabilization and heaving-branch flutter," Journal of Wind Engineering and Industrial Aerodynamics, vol. 83, no. 1, pp. 289-299, 1999.

[6] R. H. Scanlan, "Amplitude and turbulence effects on bridge flutter derivatives," Journal of Structural Engineering, vol. 123, no. 2, pp. 232-236, 1997.

[7] M. Noda, H. Utsunomiya, F. Nagao, M. Kanda, and N. Shiraishi, "Effects of oscillation amplitude on aerodynamic derivatives," Journal of Wind Engineering and Industrial Aerodynamics, vol. 91, no. 1, pp. 101-111, 2003. 
[8] G. Diana, D. Rocchi, T. Argentini, and S. Muggiasca, "Aerodynamic instability of a bridge deck section model: linear and nonlinear approach to force modeling," Journal of Wind Engineering and Industrial Aerodynamics, vol. 98, no. 67, pp. 363-374, 2010.

[9] G. Gao, L. Zhu, W. Han, and J. Li, "Nonlinear post-flutter behavior and self-excited force model of a twin-side-girder bridge deck," Journal of Wind Engineering and Industrial Aerodynamics, vol. 177, pp. 227-241, 2018.

[10] T. Argentini, D. Rocchi, and C. Somaschini, "Effect of the lowfrequency turbulence on the aeroelastic response of a longspan bridge in wind tunnel," Journal of Wind Engineering and Industrial Aerodynamics, vol. 197, Article ID 104072, 2020.

[11] B. Wu, X. Chen, Q. Wang, H. Liao, and J. Dong, "Characterization of vibration amplitude of nonlinear bridge flutter from section model test to full bridge estimation," Journal of Wind Engineering and Industrial Aerodynamics, vol. 197, Article ID 104048, 2020.

[12] Y. Wang, X. Chen, and Y. Li, "Nonlinear self-excited forces and aerodynamic damping associated with vortex-induced vibration and flutter of long span bridges," Journal of Wind Engineering and Industrial Aerodynamics, vol. 204, Article ID 104207, 2020.

[13] M. Zhang, F. Xu, Z. Zhang, and X. Ying, "Energy budget analysis and engineering modeling of post-flutter limit cycle oscillation of a bridge deck," Journal of Wind Engineering and Industrial Aerodynamics, vol. 188, pp. 410-420, 2019.

[14] M. Zhang, F. Xu, and Y. Han, "Assessment of wind-induced nonlinear post-critical performance of bridge decks," Journal of Wind Engineering and Industrial Aerodynamics, vol. 203, Article ID 104251, 2020.

[15] P. J. McKenna and W. Walter, "Nonlinear oscillations in a suspension bridge," Archive for Rational Mechanics and Analysis, vol. 98, no. 2, pp. 167-177, 1987.

[16] P. J. McKenna and W. Walter, "Travelling waves in a suspension bridge," SIAM Journal on Applied Mathematics, vol. 50, no. 3, pp. 703-715, 1990.

[17] P. J. McKenna, "Large torsional oscillations in suspension bridges revisited: fixing an old approximation," The American Mathematical Monthly, vol. 106, no. 1, pp. 1-18, 1999.

[18] P. J. McKenna and K. S. Moore, "Multiple periodic solutions to a suspension bridge ordinary differential equation," in Proceedings of the Conference on Nonlinear Differential Equations, vol. 5, pp. 183-199, Coral Gables, FL, USA, 1999.

[19] P. J. McKenna and C. Ó. Tuama, "Large torsional oscillations in suspension bridges visited again: vertical forcing creates torsional response," The American Mathematical Monthly, vol. 108, no. 8, pp. 738-745, 2001.

[20] P. J. McKenna and K. S. Moore, "The global structure of periodic solutions to a suspension bridge mechanical model," IMA Journal of Applied Mathematics, vol. 67, pp. 459-478, 2002.

[21] K. S. Moore, "Large torsional oscillations in a suspension bridge: multiple periodic solutions to a nonlinear wave equation," SIAM Journal on Mathematical Analysis, vol. 33, no. 6, pp. 1411-1429, 2002.

[22] D. S. Woolston, H. L. Runyan, and T. A. Byrdsong, Some Effects of System Nonlinearities in the Problem of Aircraft Flutter, National Advisory Committee for Aeronautics, Boston, MA, USA, 1955.

[23] D. S. Woolston, H. L. Runyan, and R. E. Andrews, "An investigation of effects of certain types of structural NonHnearities on wing and control surface flutter," Journal of the Aeronautical Sciences, vol. 24, no. 1, pp. 57-63, 1957.
[24] S. J. Price, B. H. K. Lee, and H. Alighanbari, "Poststability behavior of a two-dimensional airfoil with a structural nonlinearity," Journal of Aircraft, vol. 31, no. 6, pp. 1395-1401, 1994.

[25] S. J. Price, H. Alighanbari, and B. H. K. Lee, "The aeroelastic response of a two-dimensional airfoil with bilinear and cubic structural nonlinearities," Journal of Fluids and Structures, vol. 9, no. 2, pp. 175-193, 1995.

[26] T. O’Neil, H. Gilliatt, and T. Strganac, "Investigations of aeroelastic response for a system with continuous structural nonlinearities," in Proceedings of the 37th Structure, Structural Dynamics and Materials Conference, Salt Lake, UT, USA, April 1996.

[27] F. X. Chen, Y. M. Chen, and J. K. Liu, "Equivalent linearization method for the flutter system of an airfoil with multiple nonlinearities," Communications in Nonlinear Science and Numerical Simulation, vol. 17, no. 12, pp. 4529-4535, 2012.

[28] F. Chen, J. Liu, and Y. Chen, "Calculations of the bounds on limit cycle oscillations in nonlinear aeroelastic systems based on equivalent linearization," Science China Technological Sciences, vol. 57, no. 6, pp. 1249-1256, 2014.

[29] F. Chen, J. Liu, and Y. Chen, "Flutter analysis of an airfoil with nonlinear damping using equivalent linearization," Chinese Journal of Aeronautics, vol. 27, no. 1, pp. 59-64, 2014.

[30] E. Dowell, J. Edwards, and T. Strganac, "Nonlinear aeroelasticity," Journal of Aircraft, vol. 40, no. 5, pp. 857-874, 2003.

[31] J. R. Wright, J. E. Cooper, J. R. Wright, and J. E. Cooper, Introduction to Aircraft Aeroelasticity and Loads, Vol. 20, John Wiley \& Sons, Hoboken, NY, USA, 2008.

[32] Y. M. Chen and J. K. Liu, "Limit cycle oscillation of bridge decks with a cubic pitching stiffness," in Proceedings of the 4th National Conference on Structural Vibration and Dynamics, Patras, Greece, 2011.

[33] J. E. Younger, "Miscellaneous collected airplane structural design data, formulas, and methods," Air Corps Information Circular, vol. 7, no. 644, pp. 1-9, 1930.

[34] J. E. Younger, Metal Wing Construction, Part II-Mathematical Investigation, Material Division, Army Air Corps, Ohio, OH, USA, 1930.

[35] P. Kuhn, Stress Analysis of Beams with Shear Deformation of the Flanges, UNT Libraries Government Documents Department, Denton, TX, USA, 1937.

[36] X. W. Ma, Structural System and Composite Girder Behavior of Multi-Span Suspension Bridges, Tsinghua University, Beijing, China, 2016.

[37] H. Ashley, D. O. Neilson, and G. Zartarian, Investigation of Certain Unsteady Aerodynamic Effects in Longitudinal Dynamic Stability, Wright Air Development Center, Air Research and Development Command, United States Air Force, Baltimore, MD, USA, 1951.

[38] B. Etkin and L. D. Reid, Dynamics of Flight, Vol. 2, Wiley, Hoboken, NY, USA, 1959.

[39] Y. J. Ge and H. Tanaka, "Aerodynamic flutter analysis of cable-supported bridges by multi-mode and full-mode approaches," Journal of Wind Engineering and Industrial Aerodynamics, vol. 86, no. 2, pp. 123-153, 2000.

[40] Y. J. Ge and H. F. Xiang, "Computational models and methods for aerodynamic flutter of long-span bridges," Journal of Wind Engineering and Industrial Aerodynamics, vol. 96, no. 10-11, pp. 1912-1924, 2008.

[41] G. Gao, L. Zhu, J. Li, and W. Han, "Application of a new empirical model of nonlinear self-excited force to torsional vortex-induced vibration and nonlinear flutter of bluff bridge 
sections," Journal of Wind Engineering and Industrial Aerodynamics, vol. 205, Article ID 104313, 2020.

[42] J. Ko, T. W. Strganac, and A. J. Kurdila, "Stability and control of a structurally nonlinear aeroelastic system," Journal of Guidance, Control, and Dynamics, vol. 21, no. 5, pp. 718-725, 1998.

[43] T. W. Strganac, J. Ko, D. E. Thompson, and A. J. Kurdila, "Identification and control of limit cycle oscillations in aeroelastic systems," Journal of Guidance, Control, and Dynamics, vol. 23, no. 6, pp. 1127-1133, 2000.

[44] G. Hong, Identifying Long-Span Bridge Flutter Derivatives Via the Free Vibration Method Based on the Fluent Software, Chang'an University, Xian, China, 2012.

[45] R. E. Mickens, "A combined equivalent linearization and averaging perturbation method for non-linear oscillator equations," Journal of Sound and Vibration, vol. 264, no. 5, pp. 1195-1200, 2003.

[46] C. Runge, "Ueber die numerische Auflösung von Differentialgleichungen," Mathematische Annalen, vol. 46, no. 2, pp. 167-178, 1895.

[47] W. M. Kutta, "Beitrag zur Naherungsweisen integration totaler differentialgleichungen," Zeitschrift für Mathematik und Physik, vol. 46, pp. 435-453, 1901.

[48] M. Gu and H. Xiang, "Optimization of TMD for suppressing buffeting response of long-span bridges," Journal of Wind Engineering and Industrial Aerodynamics, vol. 42, no. 1, pp. 1383-1392, 1992.

[49] M. Gu, H. F. Xiang, and A. R. Chen, "A practical method of passive TMD for suppressing wind-induced vertical buffeting of long-span cable-stayed bridges and its application," Journal of Wind Engineering and Industrial Aerodynamics, vol. 51, no. 2, pp. 203-213, 1994. 